University of Rhode Island

DigitalCommons@URI

Open Access Master's Theses

1990

\title{
The Roots and Method of Phenomenological Realism
}

James M. Dubois

University of Rhode Island

Follow this and additional works at: https://digitalcommons.uri.edu/theses

\section{Recommended Citation}

Dubois, James M., "The Roots and Method of Phenomenological Realism" (1990). Open Access Master's Theses. Paper 1545.

https://digitalcommons.uri.edu/theses/1545

This Thesis is brought to you for free and open access by DigitalCommons@URI. It has been accepted for inclusion in Open Access Master's Theses by an authorized administrator of DigitalCommons@URI. For more information, please contact digitalcommons-group@uri.edu. 
THE ROOTS AND METHOD OF

PHENOMENOLOGICAL REALISM

BY

JAMES M. DUBOIS

A THESIS SUBMITTED IN PARTIAL FULFILLMENT OF THE REQUIREMENTS FOR THE DEGREE OF MASTER OF ARTS

IN

PHILOSOPHY

UNIVERSITY OF RHODE ISLAND

1990

$\# 24621277$ 


\section{ABSTRACT}

This thesis is concerned with answering the following question: What is phenomenological realism? I have tried to accomplish this, in part, by looking at the history of phenomenological realism. However, it is not sufficient to look at the history of this movement if we are to understand what it is today. Thus, I have tried to present the reader with the attitude, methods, and the ontological and epistemological foundations of phenomenological realism, both in some of their early formulations and in their later, more refined forms. While many phenomenological realists differ with regards to certain issues, I think that there exists much agreement concerning these basic aspects of the philosophy.

I have tried to present these foundational aspects of phenomenological realism using the following outline. Chapter one concerns itself. with phenomenological realism as a twentieth century philosophy. I mention the leading figures of this movement, both in the Munich and Goettingen Circles, and I use the works of Adolf Reinach and Dietrich von Hildebrand in order to demonstrate the attitude which is at the heart of this philosophy. I then proceed, in 
chapter two, to present the ways in which Plato's writings implicitly contain many of the notions which are vital to phenomenological realism. In chapter three I argue that the term 'phenomenological realism' does not accurately describe this philsophy and suggest that the term which Fritz Wenisch has proposed, 'chreontic philosophy,' more accurately decribes this movement. I then present three examples of how the attitude and methods of chreontic philosophy have been used to uncover certain features of reality. Finally, I conclude with responses to three objections concerning insight and the existence of genuine essences. 
TABLE OF CONTENTS

ABSTRACT .........................

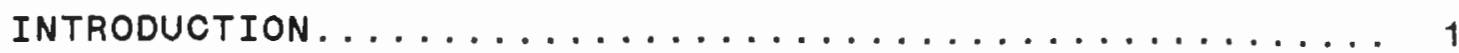
Chapter

1. PHENOMENOLOGICAL REALISM: A TWENTIETH CENTURY PHILOSOPHY......................... 4

2. PHENOMENOLOGICAL REALISM: AN ANCIENT PHILOSOPHY.. 17

3. PHENOMENOLOGICAL REALISM: A CHREONTIC PHILOSOPHY. 28

4. CHREONTIC PHILOSOPHY: THREE EXAMPLES OF ITS USE.. 44 Adolf Reinach's Analysis of Promise - a Social Act Max Scheler on the Sociology and Phenomenology of Ressentiment

Dietrich von Hildebrand: On the Heart - A Third Center of the Person

5. REPLIES TO THREE OBJECTIONS .............. 66 On the Method of Philosophical Argumentation Concerning Brentano's Reism The Third Man Argument 


\section{INTRODUCTION}

Phenomenological realism, unlike many modern schools of thought, has concerned itself with pursuing eternal, changeless, and absolutely certain truths. It is a philosophy which shares much in common with classical philosophy, particularly with regard to the Platonic notion of intuition into genuine essences. Nevertheless, one of the most distinguishing marks of the philosophers who have worked within this tradition is their keen awareness of the methods and objects of philosophy, an awareness which was often lacking among the ancients.

This thesis aims at answering the following question: What is phenomenological realism? In part, I have sought to answer this question by examining the historical roots of this philosophy, however, this thesis is not a history of phenomenological realism. My main concern is with presenting the attitude, methods, and the ontological and epistemological foundations of this philosophy. Historically, I am only interested in tracing the development of these foundations. A thorough history of phenomenological realism would include a look at the writings of Alexander Pfaender, Edith Stein, Hedwig Conrad-Martius, Roman Ingarden, Moritz Geiger, and most of 
all Husserl's Logical Investigations. Husserl is unquestionably seen as the 'Father of Phenomenology; ' however, the philosophy about which I am writing has very little in common with what most people associate with Husserl's phenomenology.

While it is widely debated, I hold that Husserl abandoned his commitment to true phenomenology when he turned from realism to a transcendental idealism. However, I wish to avoid this dispute completely. One of the best expositions of the view that Husserl made a turn from realism to idealism can be found in Josef Seifert's Back to Things in Themselves and I would strongly recommend its reading to anyone interested in phenomenological realism. 1

We find the following passages in von Hildebrand's What is Philosophy?. Referring to phenomenology, he states that it is:

the approach which is at the basis of every great philosophical discovery, whether found in Plato's Meno, Aristotle's Organon, or in the 'si fallor, sum' argument of st. Augustine. 2

Thus, phenomenology seems not to be something new. And yet, because former philosophers used this arch-method of philosophy only occasionally, and always unsystematically, without being conscious of it as a method, we may say that phenomenology is new and even revolutionary. 3

What is this arch-method of philosophy which is in some ways classical and in other ways new? In order to answer this question I will devote the first chapter to phenomenological realism as a twentieth century philosophy, and the second chapter to phenomenological realism as an 
ancient philosophy--specifically, a form of refined Platonism.

After looking at phenomenological realism as both a twentieth century and an ancient philosophy, I will consider the name 'phenomenological realism' and evaluate whether it accurately describes this kind of philosophy. I will then turn to the writings of Reinach, Scheler, and von Hildebrand in order to demonstrate how the attitude and methods of phenomenological realism have been used to 'uncover' reality. Specifically, we will look at sections of Reinach's Apriori Foundations of Civil Law, Scheler's Ressentiment, and von Hildebrand's theory of the person as found in his book entitled The Heart.

Finally, I shall respond to three objections which have been raised concerning the method of insight and the existence of genuine essences. In such a fashion I hope to delineate the roots and method of phenomenological realism. 
CHAPTER ONE

PHENOMENOLOGICAL REALISM: A TWENTIETH CENTURY PHILOSOPHY

Phenomenological realism finds its earliest

presentation in Husserl's Logical Investigations; a piece of writing which was wholly devoid of the idealist and subjectivistic notions which are found throughout his later phenomenological works. "In fact," writes von Hildebrand about the Logical Investigations, "the historical impact of this work of Husserl, attracting students of all countries to Goettingen, was due to its unambiguous refutation of psychologism, subjectivism, and all types of relativism." 4

While this work of Husserl may have started the wheel turning; it seems that phenomenology grew as a philosophy through the seminal discussions and debates which were regularly held by members of two philosophical circles: the Munich Circle and the later Goettingen Circle. While Goettingen eventually became the famed phenomenological circle, Herbert spiegelberg says of the Munich group that:

its beginnings reach back even before that of the Goettingen group, and its importance for the development of the Movement was at one time perhaps even greater. It also continued for a longer period, without rifts, shifts, and defections which marked the the history of Husserl's immediate following in Goettingen and later in Freiburg." 5 
It is this Munich Circle which is identified as the center of early phenomenology and which provided the first fruits of the type of philosophy which is the focus of this thesis.

Originally formed around Theodor Lipps' descriptive psychology, the Munich Circle was soon converted to the philosophy of Husserl's Logical Investigations after Lipps tried unsuccessfully to defend his psychologism against Husserl's refutations. Its members included Alexander Pfaender and Johannes Daubert as early leaders, Adolf Reinach, Theodor Conrad, Max Scheler and "among the younger Scheler-inspired members Dietrich von Hildebrand was the most prominent." 6

Herbert spiegelberg tells us that besides being more gregarious and meeting more frequently than the Goettingen Circle, "the most distinguishing characteristic of the Munich Circle was the primary interest in analytic and descriptive psychology, and, partly under the influence of the genius loci of the art city Munich, a stronger interest in problems of value and of esthetics than was found in the more austere mathematical and scientific climate of Goettingen."7 It is interesting to note that while today we find a clear, and sometimes hostile rift between 'continental' and 'analytic' philosophers, no such rift was to be found in the early days of phenomenology. This tendency of the Munich Circle to combine both the analytic and the descpriptive method in their psychology has not 
been lost in the development of realist phenomenology.

A futher note which should be made concerning the early circle of phenomenolgy is that the Munich and Goettingen circles were not even remotely closed. Much interaction between the two was to be found. In fact, in his history of the phenomenological movement spiegelberg tells us that the later Goettingen Circle was led by many of the earlier Munich philosophers. Among them he includes Adolf Reinach, Johannes Daubert, Theodor Conrad and Dietrich von Hildebrand. To these were later added Edith Stein, Roman Ingarden, Hedwig Conrad-Martius and eventually Max Scheler. Giving further evidence to the fact that realist phenomenology was soon abandoned by, or perhaps never fully grasped by Husserl, Spiegelberg states that:

About 1907 these students began to form a special circle. They used to meet at least once a week for discussions and the reading of papers outside the lecture halls and seminar rooms, mostly in Husserl's absence and, as a matter of fact, with his hardly concealed disapproval. For to this lively group and to its varying membership and fringe, phenomenology meant something rather different from what it did to Husserl at this stage, i.e., not the turn toward subjectivity as the basic phenomenological stratum, but toward the 'Sachen,' understood in the sense of the whole range of phenomenon, and mostly toward the objective, not the subjective ones. 8

And later he adds that "increasingly it was the phenomenology of Reinach (who had become Privatdozent in 1909) which expressed the spirit of the group." 9 Thus, while realist phenomenology is more frequently associated with the Munich Circle, we see that the later Goettingen Circle, particularly under the leadership of Adolf Reinach, 
was clearly committed to a realist view; and much to Husserl's dismay they did not adhere to his transcendental idealism.

If the early phenomenological circles did not dedicate themselves to Husserl's transcendental idealism, what did they dedicate themselves to? What was Reinach's brand of phenomenology? In order to answer this question we will take a look at Reinach's article Concerning Phenomenology and von Hildebrand's What is Philosophy?

Reinach begins his discussion of phenomenology by telling us that he does not want to talk about phenomenology but rather he wants to think in a phenomenological manner. He speaks of phenomenology as a way of seeing or an attitude. What he is referring to is the original maxim of phenomenology coined by Husserl: 'Back to things themselves'. This attitude is one which should be used both inside and outside of the realm of philosophy. Exemplifying this attitude, von Hildebrand states that the phenomenologist:

sharply disagrees, therefore, with, say, the historian of art who believes that he will attain a real knowledge of a work of art, simply by exploring all sociological influences on an artist and his work, and by minutely analyzing the history of his life. He would charge the historian with proceeding in a typically non-phenomenological way. On the other hand, the one who approaches the work phenomenologically concentrates on the very nature of the work of art itself, its beauty, its atmosphere, and tries to grasp the specific character and individuality of this work by an intuitive diving into it. 10

In the footnote to this passage von Hildebrand goes on 
to make an important point concerning the claims of certainty which arise from phenomenological

investigations--claims which are made even in the face of widespread disagreement among philosophers. He states that it "is a great and widespread error to assume that the objectivity and validity of a truth depend upon the fact that everyone and anyone can grasp it or that we can prove it in such a way that everyone must accept it." 11 Thus, the fact that this method of intuitively grasping the essence of an object presupposes certain capacities within the philosopher himself does not render it invalid or even insufficient .

For Reinach, the philosophical method is nothing other than this phenomenological way of seeing, this attitude which we may assume when we approach objects, an attitude which allows us to put aside prejudices and preconcieved notions, and then proceed to see the object in itself as it most truly is. Further, this method need not be epistemologically or metaphysically justified in order to be used fruitfully (even though an epistemological justification is possible and desirable). In his opening paragraph Reinach states that:

the essential point is this, that phenomenology is not a system of philosophical propositions and truths--a system in which all who call themselves phenomenologists must believe, and which I could prove to you--but rather it is a method of philosophizing which is required by the problems of philosophy." 12

Perhaps at this point we must distiguish realist 
phenomenology as a new system from phenomenology as a method; for this method has been justified and has produced certain truths which have become an essential part of the system of realist phenomenology.

The fact that phenomenological realism has evolved into an 'open system' of philosophy is undeniable. I say an 'open' system because it is not a system which claims to be complete, nor one which shuns dialogue with other schools of thought. But it has become a system. This can most clearly be seen when we consider the work which is being done in the area of phenomenological realism today.

The Internationale Akademie fur Philosophie (IAP) in Liechtenstein, under the direction of Josef seifert, has become a center of this strain of philosophical thought. While undoubtedly committed to a phenomenological tradition of realism, the openness of realist phenomenology becomes especially clear when one considers their list of visiting professors which represents thinkers from the most diverse areas of philosophy. In America, we find phenomenological realism represented by several philosophers at the University of Rhode Island, (including the chairman), and several others at the Franciscan University of Steubenville, (including the Dean of Faculty). All of these philosophers combine to form a tight knit circle of thinkers who are committed to the phenomenological realism of Reinach, Scheler, and especially von Hildebrand.

In the foreword to the first volume of Aletheia, 
the IAP's international journal of philosophy, we find Seifert speaking for realist phenomenology as a whole when he says, "We want to grasp reality in its various connections and in its unity, to the extent that this is philosophically possible. We are convinced that the impressive unity of the system of Dialectical Materialism should be matched and far surpassed."12 While he speaks of realist phenomenology as a system of philosophy he goes on to add that above all the thematic approach is to be taken. The objects and questions of ethics, metaphysics, and epistemology, take precedence over the history of philosophy; and reality must not be forced to fit into a system, but rather, any system should follow the outline of reality.

In this sense then, it is appropriate to speak of phenomenological realism as a system of philosophy. We have not only a method--the phenomenological way of seeing--but also a circle of thinkers who have produced a body of writings using and justifying the method. While this may not have been the case during the period when Reinach first presented his paper Concerning Phenomenology, we nevertheless find many of the foundational truths which justify the method--truths which all who use the method should recognize with certainty--presented in this article.

Let us begin by examining Reinach's discussion of the nature of synthetic apriori truths, those truths which 
Fritz Wenisch of the University of Rhode Island has argued might more properly be called "necessary, informative truths". 13 As an example of such a truth, Reinach states that orange lies qualitatively between red and yellow. Using this example he states that:

I need not be referred to some sense perception, which would have to lead me to a place in the world where a case of orange, red, and yellow could be found. Because of this, not only--as is often said-does one need to perceive merely a single case in order to apprehend the a priori laws involved; in truth, one also does not need to perceive or 'experience' the single case. One need percieve nothing at all. Pure imagination suffices. Wherever in the world we find ourselves, the doorway to the world of essences and their laws always stands open to us. 14

This, however, may be an unfortunate example. While it is certainly true that one experience of the such being of a necessary essence is sufficient for apriori knowledge, as a general rule it is a contigent fact that humans need one experience of the object to be known. It is difficult to imagine a person who came to know the necessary nature of the colors red, yellow, or orange, without ever having percieved any colors. Perhaps a better example would be that of a person who came know the essential nature of love or justice through the experience of hatred or injustice. 15

Reinach then goes on to distinguish this view from views which would threaten the objectivity of the truths discovered using this method. In response to psychologism he states that "Certainly necessity has a role to play in 
the a priori, but the necessity is not one of thought. Rather, it is a necessity of being," and in conjunction with this idea he later adds that, "states of affairs" obtain (bestehen) indifferently of what consciousness apprehends them, and of whether they are apprehended by any consciousness at all. In and for itself, the a priori has not even the least thing to do with thinking and knowing." 16 It should be noted that this later point, regarding the independence of states of affairs from minds, holds equally true of contigent states of affairs as well as necessary ones.

Without a doubt, Reinach has touched upon a few fundamental truths which do, in fact, form a set of propositions which every realist phenomenologist--thinking in a phenomenological manner-- would necessarily assent to, namely, that we can make intuitive contact with essences, free from sensory experience, at any given time. Such intuitions into essences yield absolutely certain truths. These necessary truths result from a necessity of being and not from a necessity of our thoughts; their existence is fully independent of human minds which may or may not apprehend them. And to these truths he adds another, one which surprises many thinkers, when he says the following:

up to now I have been dealing with the subjectification of the a priori. No less an evil is what I have previously called the 'impoverishment' of the a priori. There are few philosophers who have not in some way acknowledged the fact of the a priori; but there are none but what have in some way reduced it to a small province of its actual kingdom... In truth, the realm of the a priori is 
incalculably large." 17

This idea is essential to phenomenological realism. Necessary truths are not restricted to the realm of mathematics or logic, but are to be found in the areas of ethics, metaphysics, epistemology, theories of the person and any other realm in which we encounter necessary essences.

In order to see this most clearly, we must turn to von Hildebrand, for Reinach is at times ambiguous concerning terminology. For example, Reinach states that "A priori laws also hold true of the material--in fact, of the sensible, of tones and colors."18 This is a misleading passage, for while I think he means only that there are necessary truths concerning essences which are exemplified in material or sensible particulars, he does not hold that all material objects possess necessary essences (although it may be said that matter, as such has a necessary essence). The former statement is wholly compatible with phenomenological realism while the latter is not. As matter of fact, von Hildebrand writes that "what is perhaps especially new in phenomenology is that this method is used, not only de facto, but epistemologically founded and legitimated by means of the all-important distinction between genuine essences and mere morphic unities." 19

This distinction between morphic unities and genuine, necessary essences is one of the most important ideas in realist phenomenology, and while it may be implicitly found 
in the writings of Reinach, it is von Hildebrand who explicitly states it. It is a distinction which is perhaps worth mentioning at this point.

Morphic unity can be found in objects such as tables, stones, and water. All of these objects possess a meaningful unity, they are not just chaotic masses, but rather, they are objects which can be spoken of universally. They constitute 'types' or 'kinds' of objects. However, all of these objects require many experiences of them in order to come to know what holds true of them as universals. It is primarily with these objects that science deals. It is possible to state truths about the nature of such unities, but such knowledge is always tentative and never known to be necessarily true. Thus, these objects cannot be known apriori.

On the other hand, von Hildebrand cites three unmistable marks of the apriori: 1) strict intrinsic necessity; 2) incomparable intelligibility, and 3) the capacity to be known with absolute certainty. These three marks of the apriori are intimately related to and dependent upon the necessary essence of the object of any given apriori truth. In contrast to these necessary truths are merely factual truths. With regards to factual truths I merely state 'how it is', but concerning necessary truths I state 'how it must be.' And this 'how it must be' can only be seen when we are dealing with necessary essential unity. Such is the unity found in the nature of the square, love, 
moral law, and logic.

Again, it does seems that von Hildebrand must be credited with formally making this distiction between morphic unities and necessary essences. However, this distinction is found implicit in Reinach's writings, and, to the best of my knowledge, Reinach never actually violates this distinction. For example, in his statement that apriori truths hold of the material he refers the reader to the examples of tones and colors, both of which possess necessary essences and thus, their natures can be known apriori. In his discussion of objects which can be known apriori, he never presents us with a morphic unity, with the example of a table, a car, or a stone. Further, in his defense of the broad field of the apriori, he states that in all of his examples, "Existence is never posited." 20 The fact that we can 'bracket' the actual existence of the objects about which he concerns himself tells us that he acquires his knowledge of the objects not through sensible contact with contingent objects, but through an intuitive contact with necessary essences.

In such a fashion, Reinach and von Hildebrand delineate the method of phenomenology. And in combining Husserl's maxim "back to things themselves" with the idea of intuition into necessary essences, we touch upon the very core of realist phenomenology. While many realist phenomenologists are open to the Thomistic/Aristotelian notion of essences with regards to morphic unities, they 
most sharply distinguish themselves from Aristotelians, nominalists, and reists, in their notion of necessary essences. If we are to find any notion of intuition into necessary essences throughout the history of philosophy, then we must look to the Platonic tradition. 
CHAPTER TWO

PHENOMENOMLOGICAL REALISM: AN ANCIENT PHILOSOPHY

In many ways I view phenomenological realism as nothing more than a refined form of Platonism. In what follows, I will try to show a few examples of how Plato can be seen as the precursor to phenomenological realism. While it is quite clear that Plato never explicitly presents us with many ideas which are central to phenomenological realism, and that he probably was not consciously aware of many of the finer distinctions which we find in this philosophical movement, Plato did in fact raise many questions which cut to the heart of reality, and he postulated a theory of being which provides the basis of much phenomenological realist thought. Further, in the Platonic dialogues, we find many philosophical errors being uncovered, errors which must be avoided today as well. In these questions, theories of being, refutations of false doctrines, and above all, Plato's burning love for wisdom, we find the foundations of phenomenological realism.

I would like to begin by looking at a passage of the Republic. From this one passage we can draw out at least four ideas which are central to phenomenological realism.

As for those who contemplate many beautiful things but do not see Beauty itself and are incapable of following another who leads them to it, who see many 
just actions but not Justice itself, and so with everything--these people, we shall say, opine overything but have no knowledge of anything they opine.--Of necessity. What of those who in each case contemplate the things themselves which are always in every way the same? Do these have knowledge, not opinion?--That too necessarily follows. 21

Let us begin with the very first line. In it we find the distinction between particulars--many beautiful things and many just actions--and forms-Beauty itself and Justice itself. These forms exist independently of the particulars, and unlike the particulars, these things themselves are always in every way the same. This is the first and perhaps most important notion for phenomenological realism: there exist timeless and unchanging forms which do not in any way depend upon our knowing them or the particulars which exemplify them.

A second notion in connection with the forms is found in the responses which are given to Plato's questions about the nature of the knowledge which can be gained of these forms. The answer is: "of necessity," or later, "that too necessarily follows." The answer is not: "to date, that seems to be the case," or, "that is highly probable," but rather, "of necessity." This then, is another feature of the forms which Plato investigates (although it is not a feature of all objects which he speaks of universally)--the feature of necessity.

The third idea found in this passage is one which we encountered in one of von Hildebrand's footnotes concerning the phenomenological method, namely, that some people are 
unable to "see Beauty itself and are incapable of following another who leads them to it." The objectivity of the knowledge of forms is not jeopardised by the fact that not all persons are capable of intuition into essences--even with the aid of a philosopher.

The fourth concept, one which is the foundation of the phenomenological attitude, is found in Plato's question as to the knowledge of "those who in each case contemplate the things themselves which are always in every way the same." Thus, when Husserl demands a return "Back to things themselves" we correctly understand it as a return to Plato's method of investigation, a method in which we must "in each case contemplate the things themselves." Further, these things themselves--the objects of philosophy--are eternal, changeless forms, objects which yield knowledge and not mere opinion.

Thus, from this one passage of the Republic we have uncovered four general principles which underlie phenomenology: 1) There are timeless and unchanging essences which can be known by human minds but do not depend upon human minds or the particulars which exemplify them; 2) with regards to the Forms which Plato actually investigates, we find knowledge which follows with necessity; 3) the objectivity of such knowledge is not jeopardised by the fact that not all people can "see" or make intuitive contact with essences; 4) philosophers must concern themselves with the things themselves--eternal, 
changeless Forms.

Nevertheless, it seems that phenomenological realism differs from Plato's philosophy in two very important ways. First, even if the phenomenologist refers to Platonic essences, he or she claims to know these essences through intuitive contact with them, not through recollection. Second, although we do not find the distinction explicitly made until von Hildebrand, the distinction between necessary essences, meaningful universals, and accidental unities is now the ontological foundation of phenomenological realism's theory of knowledge, and thus, we may ask if there is any anticipation of this distinction in the writings of Plato.

In order to answer the first question, I would like to take a look at the Meno, for it is in this work that the doctrine of recollection is first introduced and it is here that we can gain some idea as to why Socrates proposes recollection as a method of knowledge. We find Socrates responding to Meno with the following:

Do you realize what a debater's argument you are bringing up, that a man cannot search either for what he knows or for what he does not know? He cannot search for what he knows--since he knows it, there is no need to search--nor for what he does not know, for he does not know what to look for. 22

It is in response to this problem that socrates introduces the notion of recollection, a doctrine which he tells us he learned from priests and priestesses and thought both true and beautiful. However, it is important 
to focus upon the conclusion which he draws at the end of his presentation of the doctrine of recollection.

I do not insist that my arguement is right in all other respects, but I would contend at all costs both in word and deed as far as I could that we will be better men, braver and less idle, if we believe that one must search for the things one does not know, rather than if we believe that it is not possible to find out what we do not know and that we must not look for it. 23

Now, when one understands the doctrine of recollection in this way--as a hypothesis which is proposed and believed (and claims are made only to the effect that he believes this theory not that he knows it) so that we may have some kind of justification for our search for and claims to have attained knowledge--then we find that Plato does not differ as greatly from the phenomenological realist as one might initially think. However, many phenomenological realists would differ from Plato in that they would hold that the epistemological/ontological theory of intuition into necessary essence is more than a plausible belief - it can be deductively proven using absolutely certain premises.

Concerning the second question, as to whether or not Plato's writings implicitly contained the distinction between necessary essences, meaningful universals, and accidental unities, it seems that we can say that there is a period of Plato's thinking during which he did not seem to be aware of this distinction, however, at the time when he wrote the Parmenides it appears that he had some awareness of this distinction. This can be shown if we 
compare a portion of the Parmenides with the relevant sections of von Hildebrand's What is Philosophy.

We must first ask ourselves which objects fall under the distinct categories of necessary essences, meaningful universals and accidental unities. Of the accidental unities von Hildebrand tells us that there "are unities which are indeed possible, but which, with respect to the connection of their elements, are impoverished in meaning--purely accidental, like a heap of stones or a group of random tones which do not make up a melody." 24

Concerning meaningful universals von Hildebrand gives us the examples of "gold, metal, stone or water. These objects have a meaningful nature, a quiddity which justifies our speaking of them as real types. Their unity forms the basis for a true universality." 25 However, this universality is known through abstraction; only through an inductive leap do we reach truths of a general nature concerning such objects.

Finally, with regards to necessary essences von Hildebrand tells us that when "we deal with objects like a triangle, a person, will, love, and so forth, we are confronted with a totally new and different type of unity. These objects bring us to the stage of necessary unity." 26 In contrast to merely meaningful universals, von Hildebrand tells us that one of the distinguishing marks of necessary essences is the fact that "we are given the species concretely in the single thing." 27 Thus, apriori knowledge, 
properly understood, is made possible.

Keeping in mind the examples of the three different levels of unity as distinguished by von Hildebrand, let us look at the following passage found in the Parmenides, paying special attention to the objects in question and Socrates' corresponding responses.

This passage begins with Parmenides questioning Socrates as to whether or not he holds that there are forms, or characters, for certain objects--forms which exist independently of the particulars which exemplify them. Socrates replies affirmatively and Parmenides continues with his examination of Socrates in the following manner:

And characters of this sort too? said Parmenides. For example, a certain character of just, alone by itself, and of beautiful and good, and all such as those in turn?

Yes, he said.

Well, is there a character of man separate from us and all such as we are, a certain character of man itself, or fire, or even water?

I have often been in perplexity, Parmenides, he said, about whether one should speak about them as about the others or not.

And what about these, Socrates--they would really seem ridiculous: hair and mud and dirt, for example, or anything else which is utterly worthless and trivial. Are you perplexed whether one should say that there is a separate character for each of them too, a character that again is other than the sorts of things we handle?

Not at all, said Socrates. Surely those things actually are just what we see them to be, and it would be quite absurd to suppose that something is a character of them. Still, I sometimes worry lest what holds in one case may not hold in all; but when I take that stand, I retreat, for fear of tumbling undone into the depths of nonsense. So I go back to the things we just said have characters, and spend my time dealing with them. 28 
A brief comparison of this passage with von

Hildebrand's examples of necessary essences, meaningful universals, and accidental unities will show that Plato had some rough notion of these distinctions. For example, when Parmenides enquires into the ontological status of Beauty, Justice and Goodness, Socrates responds with an unambiguous 'yes', thus affirming that these do in fact comprise genuine essences or forms. Without a doubt these objects--Beauty, Justice and Goodness--would have a place along side of Love, and Will, and Triangle, in von Hildebrand's list of necessary essences. Further evidence of this is the fact that von Hildebrand has done phenomenological investigations of Love, Beauty, and Goodness, in his writings on ethics and aesthetics.

Next, Parmenides questions Socrates as to whether there exist forms for man, fire, or water and Plato responds to the effect that he himself is not sure if we should speak in terms of forms with regards to these. Here, von Hildebrand would say we have descended to the level of merely meaningful universals and he himself gives the same example of water. The only exception to this is the unity of man. Considered corporally, it would be correct to speak of man as a merely meaningful universal. However, if we consider man as a person, as a spiritual being, then we encounter necessity, and thus, we would be justified in speaking of man as a necessary essence. It is understandable that socrates was perplexed as to whether or 
not we should speak of forms for such objects. They are universals, but they lack the feature of necessity.

Finally, Parmenides enquires about the being of hair, mud, or dirt and socrates replies that there exist. no forms, only the particular things as they are. While von Hildebrand would consider dirt as such, or hair as such, to be meaningful universals, he certainly would not consider a heap of dirt, or a mussed head of hair to possess any meaningful unity, but rather the grouping would possess a merely accidental unity.

Thus, we find each of the three distinct levels of unity being presented by Parmenides, and further, we find Socrates responding in a manner which shows some kind of awareness of the distinct kinds of being which corresponds with the different kinds of objects. Further, in his searches for definitions, or his investigations of certain objects, he only concerns himself with those things which possess a necessary essence. To a large extent then, we find the same level of awareness of these distinctions in Plato's writings as we do in Reinach's writings.

There is one other important point which can be made concerning the way in which socrates responds to Parmenides' question concerning the being of mud, hair and dirt. Socrates clearly denies the existence of forms for objects such as these, yet he goes on to add something both interesting and instructive. "still, I sometimes worry lest what holds in one case may not hold in all: but when I take 
that stand, I retreat, for fear of tumbling undone into depths of nonsense." 29 Socrates did justice to the way things presented themselves to him, even though it differed greatly from both the Parmenidean and Heraclitian notions of reality. Rather than preserve a simple philosophical system, Socrates was true to Being itself. Josef Seifert explicitly states that this is a central aspect of the phenomenological attitude.

The maxim 'back to things' also implies an opposition to premature systematizations which are among the most frequent mistakes made by philosophers. The ancient type 'Procrustes' embodies an eternal inclination of the philosopher and of man in general. It is enormously tempting for the human mind to press reality into a Procrustes-bed, to cut off what does not fit into the bed and to strech 'small things' so that they will fit our ready-made bed, as Procrustes is reported to have literally done to his guests. 30

Although much more could be said of the ways in which Plato presents us with many of the foundational ideas and attitudes of phenomenological realism, I shall limit myself to just one more feature--a feature of both Plato and Socrates as persons. In Socrates, as portrayed by Plato, we find the most beautiful example of a philosopher; a true lover of wisdom. Truth is always thematic. He spent his life fighting the sophistical attitudes which perverted the tools of philosophy--rhetoric, dialectic, and most importantly, the mind. Further, the truth, once uncovered, was to be lived. This could not have been demonstrated in a clearer way; Socrates died for what he believed to be the truth. 
This attitude which concerns itself with knowing, loving, and living according to the truth, is an attitude which is striven for in phenomenological realism today, and it is an attitude which is found in the writings of plato as it is found nowhere else. 


\section{CHAPTER THREE}

\section{PHENOMENOLOGICAL REALISM: A CHREONTIC PHILOSOPHY}

In this chapter, I would like to discuss the name 'phenomenological realism', or 'realist phenomenology' as it is sometimes called, in order to determine whether or not it accurately describes this school of philosophy. It might be argued that this is not really an important issue, that, as a matter of fact, it is not even a philosophical issue, for a school of philosophy is a merely contingent object, an object which does not possess a necessary essence, and therefore, we cannot pursue insights into such an object. While I will grant that the question concerning this school's name is not, strictly speaking, a philosophical question, I will try to show that it is, nevertheless, a relatively important pragmatic question. However, apart from pragmatic motivations, it is hoped that this investigation into the name 'phenomenological realism' will reveal many different aspects of this philosophy and help put these different aspects into perspective.

Historically speaking, there is no doubt that the circle of philosophers to which Reinach, Scheler, and von Hildebrand belonged rightly deserved the title 'phenomenologists'. It was through the vital activity of 
the Munich and Goettingen Circles, largely under the direction of Reinach (in Goettingen), that the method of phenomenology became clarified and grew in popularity. These writers remained true to Husserl's earliest notions of phenomenology as presented in his Logical Investigations.

However, Husserl himself, whether it be viewed as a turn from realism or a developement of his idea of philosophy as a rigorous science, did in fact come to embrace a view of phenomenology which was highly subjectivistic. While Reinach, Scheler, von Hildebrand, and many others did not follow Husserl's turn to transcendental idealism, a large number of philosophers did. Unfortunately, both groups of philosophers, the realists and the transcendental idealists, continued to identify themselves as phenomenologists, thus, Reinach, Scheler, and von Hildebrand have come to share the common title of phenomenologist with thinkers such as the later Husserl, Merleau-Ponty, Heidegger, and Sartre.

To make matters worse, Husserl, Merleau-Ponty, Heidegger, and sartre have all risen to greater fame than any of those thinkers whom I have referred to as phenomenological realists. Thus the common philosopher understandably, although mistakenly, associates in his or her mind the name realist phenomenology with thinkers such as Sartre or Heidegger.

I will give two example of such confusions. The first 
comes from a discussion with one of my undergraduate psychology professors. Upon hearing of the International Academy of Philosophy in Liechenstein, he asked me what kind of philosophy they specialized in. When I responded that they focused upon phenomenological realism, he gave a condescending laugh and then went on to explain to me how the very name 'phenomenological realism' was a contradiction of terms. He told me that phenomenology, rather than emphasizing the existence of objective truths and entities, focused upon the individual's subjective experience. Thus, in the eyes of this psychology professor, we are able to speak meaningfully of 'phenomenological existentialism', but the term 'phenomenological realism' is ridiculous. Clearly, this man was not familiar with the earliest roots of phenomenology. However, he was quite correct in his assessment of how phenomenology is commonly understood today, arid his confusion as to the meaning of the term 'phenomenological realism' was quite understandable.

A second example, and a far more significant one, can be found in Androw Woznicki's A Christian Humanism: Karol Wojtyla's Existential Persorialism. 31 Francis Lescoe, the current president of the American Catholic Philosophical Association, says that it "is no exaggeration to say that Professor Woznicki is almost singly responsible for making Lublin Personalism known to the English speaking world." 32 Existential Personalism can be seen as an important and 
quickly growing school of thought, especially within the Catholic Church, and further, it is a philosophy which Seifert and many other phenomenological realists are quite sympathetic to. Yet, in Woznicki's book we find a whole section devoted to "phenomenology and its limitations". 33 In this section, Woznicki tries to 'protect' Wojtyla from the label of phenomenologist. He includes a quote from Wojtyla's first book, Evaluation of the Possibility of Constructing a Christian Ethics on the Principles of Max Scheler's system, in order to accomplish this task.

A Christian thinker, and specifically a theologian, although availing himself in his writings of the phenomenological experience, cannot, however, be a phenomenologist. Consistent phenomenology will reveal to him, ethical values as appearing in the experience of a person 'on the occaision' of acting. However, it will always be the task of a theologian-ethician to scrutinize the ethical value of human actions themselves, in the light of objective principles. 34

This quote reveals an unfortunate misunderstanding of the kind of phenomenology which Reinach, Scheler, and von Hildebrand are committed to. While even von Hildebrand has been known to criticize some of Scheler's ethical work, it would be wrong to see Scheler's phenomenology as being subjectivistic. Further, Wojtyla stated that consistent phenomenology will reveal "ethical values as appearing in the experience of a person 'on the occasion' of acting." This, however, is not incompatible with an investigation of ethical values as being objective, for we must not confuse the occasion on which we recognize a value with the necessary essence in which the ethical value is grounded. 
The fact that ethical values are typically revealed upon the occasion of acting should not be viewed as problematic. 35 The very thing which wojtyla states must be done, "to scrutinize the ethical value of human actions themselves, in the light of objective principles," is precisely what is done in the ethical writings of phenomenological realism as exemplified by von Hildebrand. Further, these "objective principles" themselves are understood as being grounded in the necessary essences of justice and moral goodness,--essences which are knowable to the human mind. Thus, necessarily, there is no trace of dependence upon human actions or human knowledge in order for ethical value as such to exist (although it might still be correct to say that the value of an individual moral action comes into existence only when the action is performed).

In Woznicki's book, the label 'phenomenologist', has been treated like a dirty word and apologized for. The works of the later Husserl, Merleau-Ponty, Heidegger, and Sartre, could easily be seen as writings done in a 'phenomenological' vein, and if one understands the term phenomenology in this fashion, then it is understandable why a Christian would be wary of sharing the label phenomenlogist. However, it is not only these which Woznicki has identified as phenomenologists, but also Scheler. Perhaps the attack on Scheler's phenomenology is due to certain inaccuracies found in Scheler's writings, or 
perhaps it is due to a misunderstanding of scheler's methodology on the part of Woznicki. In any case, it is my contention that the phenomenology of Reinach, Scheler, and von Hildebrand is compatible with (and perhaps foundational to) any development of a Christian ethics and philosophy in general.

"The term phenomenology has already assumed an ambiguous character today." 36 If this statement was true in 1960 when von Hildebrand first published What is

Philosophy, then it is much more true today. Von

Hildebrand himself gives the example of Quenten Lauer's confusion of Scheler's and his own phenomenology with Husserl's later transcendental idealism. Given these few examples of the confusions which have arisen from the use of the term 'phenomenology', even when referred to as 'phenomenological realism', we may rightly ask ourselves if the term accurately describes the philosophical work of Reinach, Scheler, and especially von Hildebrand.

The word itself, 'phenomenology', can be translated as a study of appearances. Thus, the very term 'phenomenology' is ambiguous. Some, such as the followers of transcendental idealism, would take this to mean that all we can come to know is the way a thing appears us as individuals, and never the way things really are. Others, however, would interpret the word 'phenomenology' as a study of what is immediately given. Clearly, this is much closer to what the phenomenological realist actually does. Nevertheless, we 
see that the term 'phenomenology' lends itself to misunderstanding .

Seifert, in the introduction to his book Back to

Things in Themselves, discusses this very problem.

Perhaps, as Fritz Wenisch proposes, another new name should be given to such a philosophy, in order to avoid the subjectivist connotations which the term 'phenomenology' might retain even in the expression, 'realist phenomenology.' He proposes chreontic philosophy -- from the Greek word, to chreon, the necessary - which has only two further disadvantages: it sounds unfamiliar and tends to sever this philosophy from Husserl's Logical Investigations and others who spoke of phenomenology; besides, it picks only one object of philosophy, the essentially necessary, as representative for the whole object of philosophy which also includes contingent existence.37

As my few examples have shown, the term 'phenomenology' has indeed retained certain subjectivistic connotations, and when one considers that realist phenomenology is strongly opposed to all forms of subjectivism and relativism, it is especially unfortunate that it is often confused with such philosophies simply because of its name. Thus, it does seem reasonable to consider a name which might better express the most central aspects of this philosophy and at the same time free it from association with thinkers such Sartre, Heidegger, the later Husserl and Merleau-Ponty.

As seifert mentions, Fritz Wenisch has suggested the term 'chreontic philosophy', which basically suggests a philosophy which is primarily concerned with intuitive analysis of necessary essences. However, seifert, as the 
above quotation indicates, has raised three criticisms of this term. The first two criticisms are that the term 'chreontic philosophy' sounds unfamiliar and it disassociates the movement from Husserl's Logical Investigations and other early phenomenologists who were key figures in the early development of realist phenomenology. In response, I have this to say: I would prefer a term which sounds unfamiliar, but accurately describes the philosophy, than one which sounds familiar, but constantly leads to confusion and the identification of a realism with various forms of idealism. It would, however, be unfortunate if this new name were to severe the philosophy from its early roots, but we must ask ourselves if this will necessarily happen. Is it not possible that a book concerning the history of chreontic philosophy could make reference to the foundational work of those who called themselves phenomenologists? Another consideration is this: as I see it, phenomenological realism must also look to Platonic realism as a part its early roots, and the name chreontic philosophy would perhaps more clearly denote this relationship.

Seifert's third criticism of the term chreontic philosophy is that it makes reference only to the study of the necessary. Thus, while it accurately describes its concern with insight into necessary essences, it does not make reference to its concern with contingent objects, such as my own existence, or the existence of other persons. 
Perhaps von Hildebrand can help us here. Von Hildebrand does state that:

the phenomenological approach is not, however, restricted to the philosophical analysis of genuine essences, that is, to philosophical apriori knowledge. It is also indispensable for the deeper understanding of many data which play a predominant role in the humanities, such as a great individual personality, or the cultural epoch of baroque, or an individual work of art like King Lear, Mozart's Don Giovanni, etc. 38

Yet, elsewhere we find von Hildebrand telling us that the phenomenology which he, Reinach, and Pfaender embrace, differs greatly from Husserl's later notion of phenomenology. Referring to his, Reinach's and Pfaender's view of phenomenology he tells us that the "phenomenological approach in this sense is chiefly synonymous with the intuitive analysis of genuine, highly intelligible essences." 39 Thus, if phenomenology is chiefly synonomous with the intuitive analysis of necessary essences, then the term chreontic philosophy is a very appropriate and accurate name for this philosophy. Further, the fact that the name emphasizes the central aspect of the philosophy, that is, the analysis of necessary essences, does not in any way imply that it denies or excludes the study of contigent existences. It merely suggests that the study of contingent existences is not the main focus of this philosophy.

Before moving on, I would like to further examine the previous two quotes from von Hildebrand, for they reveal something which I consider to be important. In both quotes 
he refers to the phenomenological approach: in the first he speaks of it as something which can be used to gain a deeper understanding of the data of the humanities, that is, a work of art, a great personality, or a cultural epoch; in the second example he speaks of it as a kind of philosophy which is chiefly synonomous with the intuitive analysis of necessary essences. What I would like to suggest is that in the first quote he is primarily making reference to phenomenology as an approach, and in the second quote is making reference to phenomenology as a brand of philosophy, one which differs from Husserl's. This distinction between phenomenology as an approach, and phenomenology as a school is seldom made explicit, and often confused. In this thesis I have been trying to uncover the roots and method of phenomenological realism a system of philsophy, yet, writers such as Reinach, Scheler, and von Hildebrand typically refer to it as a method, as an approach. In order to clarify the real method of phenomenological realism - a system of philosophy - I would like to distinguish between what $I$ see as four distinct, although closely related, aspects of phenomenological realism.

The first aspect of phenomenological realism is what I will call the phenomenological attitude. It is an attitude which desires to know a given object as it really is, to put aside all prejudices and preconceived notions, and allow the object to reveal itself to us. This 
phenomenological attitude is often referred to as the phenomenological method, the phenomenological way of seeing, or the phenomenological approach. This however, leads to much confusion, for it is not a method, it is merely an attitude, and as the early phenomenologists were so fond of pointing out, it is an attitude which should be adopted when approaching all kinds of objects, both within and outside of the field of philosophy.

Actually, one of the best expositions of this attitude is found in von Hildebrand's analysis of the fundamental moral attitude, reverence, in the Art of Living.

Describing the reverent man he says the following:

He is free from this egospasm, from pride and concupiscence. He does not fill the world with his own ego, but leaves to being the space which it needs in order to unfold the value which it already possesses in its opposition to mere nothingness. 40

He goes on to add that:

Confronted with being, the reverent man remains silent in order to give it an opportunity to speak. The man who possesses reverence knows that the world of being is greater than he is, that he is not the Lord who can do with things as He likes, and that he must learn from being, not the other way around.41

This attitude, which von Hildebrand describes as reverence, is really the foundation to what the early phenomenologists saw as phenomenology. However, even if this attitude is foundational to phenomenological realism, it is only an attitude and should not be referred to as the phenomenological method.

The second aspect of phenomenological realism, and 
perhaps the least fixed, is what can be called a way of proceeding. In his book entitled Die Philosophie und Ihre Methode, Fritz Wenisch has distinguished between the method of philosophy and a way of proceeding. 42 One may proceed in many different ways. I may begin doing philosophy by reading a philosophical work, or by fixing my mind upon an example which exemplifies the essence which I would like to analyze, or, by engaging in dialogue with a colleage. Thus, I may proceed in several different ways, and no one way of proceeding should be cited as the philosophical or phenomenological way of proceeding, (although it might be said that true phenomenology is opposed to any way of proceeding which begins by looking at a way of systematizing reality, rather than beginning by looking at reality itself).

Distinct from the way in which one proceeds is the method which one uses in philosophy. Traditionally, philosophers would cite three methods: insight or intuition, deductive reasoning, and internal perception. Phenomenological realism, like most legitimate philosophical schools, uses all three methods. Further, the methods of repeated sensory observations and inductive generalization would be viewed as belonging to the realm of science and not philosophy.

Closely related to the method of doing philosophy, is the ontological foundations and epistemological justifications of a philosophy. I would argue that the 
ontological foundations of phenomenological realism lie in the notion of timeless, changeless, immaterial, necessary essences. Epistemologically speaking, we can say that when one is presented with such genuine essences, one is. able to know these essences with certainty through intuition or insight. That intuition is possible with regards to such objects is given simultaneously with any insight. That I, myself, can clearly see necessary features of essences is known to be true through internal perception and is given during the actual experience of having an insight through lateral consciousness.

Applying what was just said, we can justify the use of deductive arguments. It is a feature of a deductive argument as such, that it possess a high degree of intelligibility and necessity. Thus, we can know that, when working with a valid argument form and true premises, we will necessarily arrive at a true conclusion (although the necessity of the truth of the conclusion may be only conditional and not absolute). In addition to this, we can say that the validity or invalidity of a deductive argument is intuitively obvious, and grounded in the nature of the genuine essence of logical entities.

Finally, while not grounded in or justified by the existence of a necessary essence, the method of internal perception can also yield absolutely certain truths. The best example of an absolutely certain truth known through internal perception is my knowledge of the fact that I 
exist. The fact that I exist, is not known or proven by a syllogism -- 'I think, therefore, I am' -- but rather, I clearly recognize with certainty that $I$ both think and exist through internal perception. The truth of these statements springs back into existence whenever I doubt them, as Augustine's 'Si fallor, sum' so clearly expresses.

Thus, we can see that phenomenological realism has four distinct, although closely related parts: an attitude, various ways of proceeding, a three-fold method, and an ontological foundation and epistemological justification of its method. At various times we find the early writers, Reinach, Scheler, and von Hildebrand, identifying phenomenology with one aspect or another, however, it would be more proper at this time to find a name (whether phenomenological realism or chreontic philosophy), which would describe the philosophy as a whole, and not just one aspect.

I would argue that the term 'phenomenology' does justice to none of these aspects. Historically, Reinach, Scheler, and von Hildebrand used this term most often to describe the attitude which I have largely identified with von Hildebrand's notion of reverence. It is only when the term phenomenology is used to refer to an attitude that we can allow Reinach to say that there are no truths which all who call themselves phenomenologist must ascribe to, for as a school of thought, there are certainly a few truths which 
all who call themselves phenomenological realists must ascribe to.

Seen as a system of philosophy, I think the term 'chreontic philosophy' is more descriptive of what has been called phenomenological realism than the term 'phenomenological realism.' 'Chreontic philosophy' refers to both the methods and corresponding epistemological justifications of insight and deductive reasoning. While internal perception is a third and legitimate method of doing philosophy, its use is not excluded by the term chreontic philosophy, it is merely not described as the central method, and this is true to the writings of Reinach, Scheler, and especially von Hildebrand.

The only legitimate problem with the term is that it does not make immediate reference to the early phenomenologists who laid the foundation of this system. However, this limitation can be largely overcome through the writing of and awareness of the history of chreontic philosophy. Further, as mentioned earlier, I do not view the roots of this method as existing solely in the early writings of Husserl and his followers, but rather, to a large extent, they also lie in the writings of Plato.

Most importantly, the term 'chreontic philosophy' avoids all confusions of this philosophy with the subjectivistic and idealistic philosophies of the later Husserl and those who followed and developed his transcendental idealism. In the promotion of 
phenomenological realism, 〈perhaps especially within theistic circles), the use of the term chreontic philosophy may be much more advantageous. 
CHAPTER FOUR

CHREONTIC PHILOSOPHY: THREE EXAMPLES OF ITS USE

In this chapter, I would like to present the reader with three examples of how chreontic philosophy has been used to uncover reality. The first example is drawn from Adolf Reinach's analyses of the nature of promise and social acts as found in his A Priori Foundations of Civil Law; the second example comes from Max Scheler's sociology and phenomenology of Ressentiment; and the third from von Hildebrand's unfolding of the nature of the person in The Heart. All three examples have relied upon the intuitive analysis of necessary essences as their primary method. They all exemplify reverent and receptive attitudes towards the essences in question. The authors put aside preconcieved notions and prejudices in order to allow the objects to reveal themselves. Thus, these examples present the reader with some of the finest products of this system of philosophy.

Due to the brevity of this thesis, I have attempted to briefly summarize small sections of these texts. I hope to present the reader with certain necessary features of the essences which are being analyzed. These are features which the individual author has discovered or brought to the 
surface, they are features which were seen by the author. I say this because it would be a terrible mistake to view these works as inventions, or the products of one who has merely stipulated that when he uses the term "x" he means "the following." These are the products of persons who have fixed a given essence before their mind and proceeded to 'describe' features which will hold true of it in every individual exemplification of it, whether or not the essence is, in reality, ever exemplified.

Unfortunately, many of the finer points of these analyses, as well as the author's style of writing, are completely lost in summaries such as these. I strongly recommend to those who are interested in phenomenological realism that they read the following texts in their entirety.

\section{A. ADOLF REINACH'S ANALYSIS OF PROMISE - A SOCIAL ACT.}

Adolf Reinach (1883 - 1917) was unquestionably one of the earliest leaders of phenomenological realism. He completed his doctoral dissertation under the direction of Theodor Lipps, and his habilitation under the direction of Edmund Husserl. Von Hildebrand says of Reinach:

In him I encountered the philosopher who made a profound impression on me by his unconditional love of truth, his intellectual power, his thoroughness, and his incomparable clarity. It was a great gift for me to discuss with him many philosophical questions. Later on in Goettingen, from 1910 on, he was my only teacher...43

Husserl himself said that Reinach "was among the first who 
could understand, creatively and perfectly, the peculiar meaning of the phenomenological method and could view it in its entire philosophical range." 44 Elsewhere he states that it "was really Reinach who introduced me to my Logische Untersuchungen, and in an excellent way." 45

Let us now turn to Reinach's analysis of the nature of promise - a social act which produces both claim and obligation - as found in his Apriori Foundations of Civil Law.

I would like to begin this summary with a quote from Reinach which presents us with the uniqueness of this investigation, a uniqueness and novelty which Reinach himself clearly saw.

We can surely take it as generally granted that there are no self - evident and necessary relations of essence in the casual relations of external events. However it is, to speak with Hume, that we come to know that fire produces smoke, this is surely not intelligibly grounded in the essence of fire, as it lies in the essence of the number 3 to be larger than the number 2. There is no doubt that the causal relation is no necessary "relation of ideas." But it would be a mistake to extend this principle to every relationship obtaining between temporally existing things. The case which is now before us is the best proof of this. A "cause" which can generate claim and obligation is the act of promising. From this act, as we shall show more exactly, proceed claim and obligation; we can bring this to evidence when we consider clearly what a promise is and when we achieve the intuition that it lies in the essence of such an act to generate claim and obligation under certain conditions. And so it is by no means experience in the sense of observation which instructs us, not even indirectly, about the existential connection of these legal entities; we have rather to do here with a self - evident and necessary relation of essence. 46

Thus, Reinach intends to do a chreontic investigation, 
an investigation of the necessary and highly intelligible essence, of promise. A promise is a "causal" temporal event, that is, it exists in time and from this act proceed claim and obligation. Thus, it is similar to fire, which also exists in time and acts as a cause of smoke. Yet, it greatly differs from fire, for the causal relation of fire to smoke is not known as self-evident, this knowledge is not due to a necessary relation between fire and smoke; but the relation between promise on the one hand, and claim and obligation on the other, is known as self-evident, due to the necessary relationship which exists between the essential natures of these objects. Thus, the nature of promise is not only interesting, but it rightly belongs to the sphere of philosophy.

Reinach begins by posing the question "What is a promise really?"

The usual answer is that promising is a declaration of will, or more exactly, an expressing or making known the intention of doing or omitting something in the interest of another to whom the utterance is made. Why this utterance should oblige and entitle is of course far from being understandable. It is after all certain that the mere intention to do something does not have any such effect. 47

As he states, the typical definitions of promise leave one wondering why claim and obligation should follow as a result of making a promise. In order to uncover the true nature of promise, Reinach investigates the essential nature of the general class of acts to which promising belongs, namely, social acts. 
There exist certains actions which reveal the self as acting. These he calls spontaneous acts and he give the examples of turning our attention to an object or making a resolution.

It would be quite a mistake to want to find the distinguishing mark of these experiences in their intentionality. The regret which rises up in me, or the hatred which asserts itself in me, are also intentional in that both refer to some object. Spontaneous acts have in addition to their intentionality also their spontaniety, which lies in this, that in them the self shows itself to be the phenomenal originator of the act. 48

Now, in this category of spontaneous acts we find two major sub-categories. The first is represented by the act of deciding. It is an internal act. It can be performed without being announced or needing to be announced to another.

The second category of spontaneous acts consists of other-directed experiences such as forgiving, or envying. I cannot envy or forgive myself, these acts must always be directed towards another.

When we consider the act of commanding we encounter yet another division, for the act of commanding requires not only that it be directed toward another, but also that it be heard. This is not the case with forgiving or envying, for I can envy or forgive someone without announcing it to another, it can, so to speak, unfold entirely within, even though it is directed towards another. However, in the case of commanding, the act requires that it be heard by another in order for it to 
fully come into existence.

Reinach states that we "designate the spontaneous acts which are in need of being heard, social acts," and it is to this category that the act of promising belongs.49 Thus, if we can unfold the nature of social acts in general, we will uncover a multitude of features which necessarily belong to the nature of a promise.

At the present, we can already say that a promise is a spontaneous act (that is, it is one in which the self shows itself to be the phenomenal originator of the act), it is intentional, it has the feature of being other-directed, and it is in need of being heard. Much more, however, can be said.

In order to uncover the nature of social acts in general, Reinach investigates the essential natures of the following acts: informing, requesting, commanding, and questioning. Each of these objects in turn has a corresponding "internally complete experience whose intentional object coincides with the intentional object of the social act or is at least somehow related to it." 50

Reinach speaks of social acts as having a body and a soul, an inner and an outer side. It is interesting to note that the outer side, the external expression - a gesture, words, or a facial expression - is a required feature among men, however, it is not a necessary feature. The feature of being heard, on the other hand, is necessary. As the example of prayer to God will show, it is possible that the 
act be heard by another with absolutely no external act.

Thus, while interacting with humans, we will always find an outer expression, a body, so to speak, which corresponds with the social act, but this is not an essential feature. For the sake of brevity, I will present some of the features of social acts only in the context of how these features relate to the nature of a promise. The following quote will reveal the depth of Reinach's investigation of the nature of a promise. In order to highlight the features which are common to all social acts (not just promising), as well as the modifications common to all social acts, I have added two sets of underlined numbers which are not found in the text.

Let us return to our starting point, the act of promising. It does not take a long explanation to show why we find promising to be an other-directed social act. ( 1 ) It inaugurates a train of events, like commanding and unlike informing. It too aims at an action, though of course not at one of the recipient of the act, but at one of the promisor himself. This action need not be a social act as in the case of questioning.

Like all social acts, (2) promising presupposes an inner experience which has the content of the promise as its intentional object. As with commanding, this inner experience is that of intending that something occur, not of course through the addressee but through the promisor himself. Every promising to do this or that, presupposes that one's will is directed to this action.

As a social act, promising admits of all the modifications which we discussed above. These are (1) promises which are directed to several persons together, or (2) performed by several together. From these acts proceed claims which several persons share together, and obligations which bind several together. Further, there is ( 3 ) a conditional promising, which we will have to distinguish sharply from (4) unconditional promising with conditional content. From the former, claim and obligation come into being only on the fulfillment of the condition, 
for only then does the promise unfold its proper efficacy. From the latter, claim and obligation come into being immediately... In addition to one's own promising, there is ( $\underline{5}$ ) promising in the name of another, a representative promising. A person performs an act of promising, but he is not the one who promises; he rather lets another promise, or more exactly, he promises for another.51

Reinach thus concludes that:

We now see clearly how thoroughly mistaken and untenable is the usual conception of promising as an expressing of intention or of will. An expression of will runs like this: I intend. If it is directed to someone, then it is an informing, which is indeed a social act but no act of promising. And of course, it does not become a promise by being directed to the one who will profit from the intended action.

Promising is neither intending nor the expression of intending; it is rather an independent spontaneous act which in turning without, expresses itself... and we claim that it lies in the essence of this act to bring forth claims and obligations.52

In such a fashion, Reinach has described the essential nature of promising, and in the process he has uncovered a whole new sphere: the realm of social acts.

MAX SCHELER: ON THE PHENOMENOLOGY AND SOCIOLOGY OF RESSENTIMENT

Herbert Spiegelberg begins his discussion of Max Scheler, (1874-1928), with the following:

There can be little question that in the early twenties before the advent of Martin Heidegger Max Scheler was in the eyes of the German public the number two phenomenologist; in fact to many he was more - a star of the first magnitude whose dazzling light revealed more than the prominent member of a new school: a philosopher of the age.53

Max Scheler undoubtedly played a major role in the formation of phenomenological realism, however, it was a 
role quite different from that of Husserl's or Reinach's. Edith stein, who was a member of the Goettingen circle, has provided us with one of our best sources of information pertaining to Scheler's activities during the formative years of phenomenology. She writes that "one's first impression of Scheler was fascination. In no other person have I ever encountered the 'phenomenon of genius' as clearly. The light of a more exulted world shone from his large blue eyes." 54 However much Stein admired Scheler, she was, nevertheless, not blind to certain features which greatly distinguished Scheler from Husserl and Reinach.

After being dismissed from the University of Munich as a result of a scandalous divorce suit, scheler depended upon his writings and his lectures in order to support himself. Largely due to the support of Dietrich von Hildebrand, Scheler was frequently invited to give lectures to the Philosophical Society at Goettingen. 55 His relationship with Husserl was often marked by tension due to several factors. Nevertheless, Scheler seems to have had a tremendous impact upon many of the students who studied under Husserl during the early days of phenomenology. Stein sums up the situation as follows:

Added to this competition for priority was Husserl's serious concern regarding his students. He took great pains to educate us to rigorous objectivity and thoroughness, to a 'radical intellectual honesty.' In contrast, Scheler's practice of scattering about ingenious suggestions without pursuing them systematically had something dazzling and seductive about it. Moreover, he chose topics of vital personal importance to his young listeners, who, consequently, were easily affected by them. Husserl on the other 
hand addressed sober, abstract matters. However, at that time in Goettingen, despite such tensions, their association was still mutually friendly.56

Apart from Husserl, Scheler is perhaps more than any other philosopher to come out of this early phenomenological circle, both the most prolific and the most well-known. In what follows I have tried to summarize the first section of his work entitled Ressentiment, a term which he borrowed from the French because he could find no suitable German equivalent. 57 This work has been highly praised and some consider it his clearest example of phenomenology done properly.

Scheler begins this investigation into the nature of resentiment ( I will use the English equivalent of the French term), with a consideration of the meaning of the word.

In the natural meaning of the French word I detect two elements. First of all, ressentiment is the repeated experiencing and reliving of a particular emotional response reaction against someone else. The continual reliving of the emotion sinks it more deeply into the center of the personality, but concomitantly removes it from the person's zone of action and expression... Secondly, the word implies that the quality of this emotion is negative, i.e., that it contains a movement of hostility. 58

Scheler presents us with a lengthy quote which demonstrates Nietzsche's use of the term, however, Scheler asks the reader to allow him to proceed with an investigation of resentiment as such, apart from the context in which Nietzsche introduces the term.

Instead of defining the word, let us briefly characterize or describe the phenomenon.

Ressentiment is a self-poisoning of the mind which 
has quite definite causes and consequences. It is a lasting mental attitude, caused by the systematic repression of certain emotions and affects which, as such, are normal components of human nature. Their repression leads to the constant tendency to indulge in certain value delusions and corresponding value judgements. The emotions and affects primarily concerned are revenge, hatred, malice, envy, the impulse to detract, and spite. 59

This one paragraph neatly summarizes two essential features of resentiment. The first feature which he presents us with is that resentiment is caused by the systematic repression of emotions which are quite normal for humans to experience. Thus, it is when feelings of vengefulness, envy, or jealousy, are systematically repressed, that resentiment is given the environment to flourish. The second feature is that resentiment leads to value delusions. The recognition of this feature is all-important, for it then allows Scheler to criticize Nietzche's claim that Christian values are based upon ressentiment.

His exploration of the normal emotions, which, when repressed lead to resentiment, is interesting. He cites the thirst for revenge as the most important source of resentiment. Revenge as such has certain features: it is a reaction; it is always preceeded by an attack; it generally is directed towards a specific object, and contains the notion of returning evil for evil.

The fact that revenge has a specific object is important. It is characteristic of the move from revenge to resentiment that the person loses focus upon a specific 
object. Here we encounter vindictiveness. We find several features which are common to vindictiveness as well: the object towards which one's feelings are directed becomes more indeterminate; the desire begins to feel 'righteous'; and is accompanied by a feeling of duty. Scheler adds that a person will not reach this level of vindictiveness if either one of two things occurs: the person forgives the wrong which was done to him, or, the person actually avenges himself. Further:

Ressentiment can only arise if these emotions are particularly powerful and yet must be suppressed because they are coupled with the feeling that one is unable to act them out - either because of weakness, physical or mental, or because of fear... If an ill-treated servant can vent his spleen in the techamber, he will remain free from the inner venom of ressentiment, but it will engulf him if he must hide his feelings and keep his negative and hostile emotions to himself.60

In a similar vein, he later adds that:

revenge tends to be transformed into ressentiment the more it is directed against lasting situations which are felt to be 'injurious' but beyond one's control - in other words, the more the injury is experienced as destiny. 61

The second major source of resentiment is envy.

'Envy', as the term is understood in everyday usage, is due to a feeling of impotence which we experience when another person owns a good we covet. But this tension between desire and nonfulfillment does not lead to envy until it flares up into hatred against the owner, until the latter is falsely considered to be the cause of our privation.62

Pointing to the only way one can avoid envy, he quotes Goethe: "against another's great merits, there is no remedy but love." 63 
In connection with envy, he cites two different types of persons: the noble man, and the common man. The most distiguishing feature between the two is this: the "noble man experiences value prior to any comparison, the common man in and through a comparison." 64 Thus, we either find the common man trying to acquire more, for the sake of being most highly esteemed, or failing to achieve this esteem, the man becomes full of resentiment and becomes subject to value delusions.

the common man seeks a feeling of superiority or equality, and he attains his purpose by an illusory devaluation of the other man's qualities or by a specific 'blindness' to these qualities. But secondly - and here lies the main achievement of ressentiment - he falsifies the values themselves which could bestow excellence on any possible objects of comparison. 65

We find this same idea elsewhere in his analysis:

we must introduce an additional psychological law. We have a tendency to overcome any strong tension between desire and impotence by depreciating or denying the positive value of the desired object. 66

Thus, because this is a "psychological law", he is able to add that this:

'falsification of the value tablets,'

'reinterpretation,' or 'transvaluation' should not be mistaken for conscious lying. Indeed, it goes beyond the sphere of judging. It is not that the positive value is felt as such and that it is merely declared to be 'bad.' Beyond all conscious lying and falsifying, there is a deeper 'organic mendacy.' 67

However common this tendency to falsify values is in man, it is nevertheless true that values can be recognized as they truly are.

Nietzsche is wrong in thinking that genuine morality springs from ressentiment. It rests on an eternal 
hierarchy of values, and its rules of preference are fully as objective and clearly 'evident' as mathematical truths. There does exist an ordre du coeur and a logique de coeur (in Pascal's words) which the moral genius gradually uncovers in history, as it is eternal - only its apprehension is 'historical.' 68

A further point which scheler makes with regards to Nietzche's ethical skepticism is that Nietzsche continually speaks of a "falsification of the value tablets," yet the very term 'falsification' implies that there exists a true set of values.

In my summary I have focused only upon the first chapter of Scheler's book entitled Ressentiment. In the text he goes far beyond the few features which I have focused upon, however, it is hoped that this summary has nevertheless presented the reader with a small intimation of the genius which is found in this book. This book points to the validity of an "apriori psychology", which of course, has been wholly abandoned by the field of psychology today. This book, however, demonstrates that the intuitive analysis of human emotions and behavior can be quite fruitful.

VON HILDEBRAND: ON THE HEART - A THIRD CENTER OF THE PERSON Dietrich von Hildebrand, (1889 - 1977), began as a student of Theodor Lipps, but soon moved from Munich to Goettingen in order to study under Husserl, Scheler, and Reinach. Both his Ethics and his What is Philosophy are philosophical masterpieces and have become 'classics' in 
the contemporary circle of phenomenological realism. While largely unknown to the world of philosophy, he is seen by many (including the present author) as the person who has most clearly presented us with the epistemology, ontology, and axiology which are foundational to chreontic philosophy. Joseph Seifert and John Crosby, in their obituary of von Hildebrand, state that, the "whole of von Hildebrand's works would fill at least twenty volumes, and this does not include his rich Nachlass... Which contains many manuscripts on problems of logic, language, causality, freedom, justice, philosophy of religion, and on other subjects. " $=9$

While von Hildebrand's notion of the heart can be found scattered throughout many of his various works, I will be working primarily with his book entitled The Heart, (although I will make some reference to his chapter on value response from his Ethics). Originally published as The Sacred Heart, it is a defense of the relatively new Roman Catholic devotion to the Sacred Heart of Jesus and an analysis of the affective sphere in general. While many parts of this book would be considered religious writing, Part One - the Human Heart, while making full use of religious examples, is actually a phenomenology of the heart, a third center of the person. When one considers that throughout the history of philosophy, only the intellect and the will have been identified as central faculties of the person, we begin to see how important von 
Hildebrand's formal presentation of the heart is.

In some respects The Heart is not the best example of von Hildebrand's philosophical writing. While most of his works are quite orderly and precise in meaning, this book is at times haphazard and slightly ambiguous. However, while the book's external order is at times rough, one finds that it has an inner order which mirrors reality and his insights into the nature of the heart are profound.

He begins his analysis by examining the role of heart and points to three main perversions of affective responses. The first, and an extremely common one, is to shift the focus from the object to the affective response. One of my undergraduate professors, James Harold, tells a story of how he first became aware of this perversion. When he first listened to Mozart he was deeply moved. He had an experience of what von Hildebrand calls "being affected" and responded with the emotions which should properly result from such an experience. His feelings were shaped by the beauty and magnificience of the music. However, when he again sat down to listen to Mozart he paid less attention to the music and focused instead on his anticipated emotional response. He soon realized that not only was this a perversion of the response, but it simply didn't work that is, he did not experience the feelings which he earlier had when focusing on the majestic music.

A second perversion occurs when we detach the response from the object and see it as having its meaning in itself. 
I think an example of this might occur when two new lovers consider the feeling of being in love as something which is valuable in and of itself, apart from the value of the beloved or the relationship with the beloved. These feelings may play an important role in the development of the relationship, but they must never be seen as valuable in themselves, detached from the beloved who motivated the feelings.

The third perversion of affective responses occurs when we reduce an affective response to something which is outside of the affective sphere. Von Hildebrand states that "This occurs for example when one makes of the liability resulting from a promise which is an objective juridical entity, a mere' feeling' of liability." 70

While von Hildebrand does briefly examine some of the faulty theories concerning the affective sphere, he does not lay the full blame on these for the way this sphere has been discredited. Also to blame is the unparallelled danger of "ungenuineness" which is to be found within the affective sphere. In an uncharacteristically Hegelian way, he again gives three examples.

The first kind of affective ungenuineness is rhetorical. "This is typified by the man who exhibits a false pathos and enjoys his indignation or his enthusiasm by inflating it rhetorically."71

The second kind of ungenuineness is the sentimental type. Such a person is "self- immersed". He or she enjoys a 
feeling for its own sake and loses focus on the motivating object.

Lastly, he speaks of the hysterical type. He calls this "classical falseness". The person is "imprisoned in an excitable egocentricity", "everything they do or say, is poisoned by an inveracity and falsity...artificially heightened and embellished." 72

The Heart is so rich in examples and insights that certainly I am not able to do it justice in a few pages, and perhaps I do von Hildebrand a disservice if one reads this summary and walks away considering himself familiar with Hildebrand's notion of the heart. Due to the brevity of this paper I shall consider only two more of von Hildebrand's ideas, however, I would like to emphasize that what I have given is certainly not a concise summary of his thought but perhaps only a poor intimation of it. Any analysis of The Heart which fails to mention the idea of "being affected", or his analysis of the many false equivocations of the word 'passions', or again, his distinction between bodily and psychic feelings versus intentional affective responses, grossly fails its task.

Central to von Hildebrand's ethics and his notion of the heart is the idea of value response. This perhaps parallels C.S. Lewis' doctrine of objective value which states that certain objects demand a specific emotional response from us. However, von Hildebrand goes much further in distinguishing the different aspects of this 
phenomenon.

For von Hildebrand, values demand an affirming response such as love, gratitude or joy, (and in some instances volitional responses as well). These responses in a manner of speaking say "yes" to their object. A young child is a good example of an object which demands such a response. This is why C.S. Lewis, in the Abolition of Man, rightly sees that his lack of affection for children is a defect in himself.

A disvalue is such that it demands a rejecting affective response such as hatred or disgust, responses that answer "no" to the object. Clearly if we witnessed a man beating on an innocent young child we should react with disgust and even anger towards this action (and if we were in a position to help the child we should also make the volitional response to try to do so). This event possesses such a clear disvalue that one would either have to be completely value blind or evil not to render the proper response. 73

Let me now clarify something. What von Hildebrand means by a value response is only an adequate response to something which possesses either a value or a disvalue. The term 'value response' seems misleading because according to its natural connotation it can be interpreted in two ways, and further, the term is insufficient for does justice to neither interpretation. The first way one could interpret the term 'value response' would be to assume that it refers 
to the object and that this object possesses a value. However, this tells us nothing about whether it was an adequate response, and further, it does not include responses to disvalues. A second understanding of the word would be to take it to mean that the response itself possesses a value. In this case, we find that it still does not accurately delineate the sphere of values, for it does not include the idea of those responses which possess a great disvalue, such as enjoying the sight of a young child being beaten.

For this reason I propose two new terms which would more clearly circumscribe the class of responses which von Hildebrand spoke of in as 'value responses': 'value carrying responses' and 'disvalue carrying responses.' When we find that we are dealing with morally relevant objects the following generalization will hold true: the former could only be good, that is, it is either the rejecting of a disvalue or the affirming of a value, and the later could only be bad, that is, it is either the rejecting of a value or the affirming of a disvalue.

It is important to note that while these new names do not contain a direct reference to the objects which motivate the responses, they do accurately tell us about the objects, for a response can only carry value if it is an appropriate response to an object which possesses value or disvalue, and similarly, a response can only possess disvalue if it is an inappropriate response to an object 
which possesses either value or disvalue. Thus these term are at least unambigous. However, one might object that they put the focus upon the responses and not the objects which motivate the responses. In such a case the only good alternative is to create four new terms, each of which should include reference to whether or not the response was adequate or inadequate and whether it was directed towards a value or a disvalue. Thus, we might speak of 1) value carrying responses to a value, 2) value carrying responses to a disvalue, 3) disvalue carrying responses to a value, and finally, 4) disvalue carrying responses to a disvalue. In any case, use of the term 'value response' should be avoided because it is clearly an ambiguous term.

Lastly, I would like to just mention the way in which von Hildebrand in his Ethics relates freedom to our affective responses. While C.S. Lewis points out that no emotion is a judgement, and thus, all emotions should be considered alogical, one might also add that no emotion is totally within our freedom and thus all emotions should be said to be amoral as well. However, just as Lewis points out that emotions are still related to reason in that they can conform or fail to conform to it, so emotions are related to the will.74 Through what von Hildebrand calls cooperative freedom one can take a free stance towards his or her emotions. A man can either say "yes" to his lustful feelings, or he can disavow them. In disavowing an emotion I say "no" to it through an exercise of my mind and my will 
and in doing so I create what can be called a "distance between the response and my free spiritual center." 75

Not only through cooperative freedom but also through indirect freedom is the will related to the heart. With indirect freedom we find that we can slowly change our character such that inappropriate responses are less frequent and appropriate ones more frequent. Through indirect freedom emotions are perhaps made a little more logical and moral. But clearly this task calls for the assistance of a good and true psychology. 


\section{CHAPTER FIVE \\ REPLIES TO THREE OBJECTIONS}

Thus far we have looked at phenomenological realism as a twentieth century philosophy, a form of Platonism, and a chreontic philosophy. We have seen in what ways it is a classical philosophy and in what ways it is a new and revolutionary philosophy. We have looked at several examples of how this method of doing philosophy and the 'phenomenological attitude' have been applied in order to uncover the nature of promise, of ressentiment, and of the human person. What we have not done is to look at some of the common criticisms of phenomenological realism and all other schools of thought which hold the existence of necessary essences and the potential of man to gain knowledge of these essences through intuition or insight. That is what this final chapter is intended to do, and I think it has its place in this study of the roots and method of phenomenological realism, for this thesis is not intended to be a purely historical study. It is largely an investigation into the nature of philosophy itself and I have presented phenomenological realism as a school of thought which has greatly contributed to a positive formulation of what the objects of philosophy are and how we can come to know them. Thus, it is only natural that I should address certain objections which have been raised against the notions of insight and Platonic essences. 
A. ON THE METHOD OF PHILOSOPHICAL ARGUMENTATION

I would like to reflect upon one of Bruce Aune's most recent papers and critically examine some of the more important ideas contained therein.

I would summarize his paper as follows: it is a brief presentation and examination of some of the most basic epistemological methods of philosophy. He states in the first paragraph that he is "concerned with only one aspect of the philosophical method, not the whole thing", and this one aspect is philosophical argumentation. However, in the course of investigating philosophical argumentation, he seems to bring into question the entire epistemological foundations of philosophy. If the arguments in his paper are sound, then they are certainly destructive to the foundations of phenomenological realism, for in this paper he argues against insight as a method of knowing, and excludes its use in philosophical argumentation. Thus, a response is in order.

His reflections begin by questioning the rigor of traditional philosophical thought and he introduces, by way of example, the long standing debate between himself (defending the soft determinism of G.E. Moore), and the agency theorists, Chisholm and Lehrer. I would like to briefly summarize this dispute and then show how Aune has used it to try to demonstrate the shortcomings of traditional argumentation.

In short, G.E. Moore tried to interpret freewill in 
such a way that it would be compatible with a metaphysical determinism. Accepting the popular definition of freewill as 'S acts freely only if $S$ can do otherwise', he went on to hypothetically interpret the sense of 'can' used in the definition. The result was this: $S$ can do $A=d f$. $S$ will do A if $S$ chooses to do so.

Both Chisholm and Lehrer responded with examples which demonstrated that Moore's analysans, that is, 'S will do A if $S$ chooses to do so', is consistent with the supposition that $S$ cannot choose to do $A$. Therefore, $S$ could not do $A$ because, according to Moore's analysis, choosing $A$ is a prerequisite for doing $A$. Chisholm and Lehrer concluded that Moore's analysandum, 'S can do A', is not consistent with such a supposition and therefore is not equivalent with its analysans. Thus, Moore's analysis is incorrect. Over twenty years ago, Aune criticized the responses given by Chisholm and Lehrer by claiming that they merely begged the question in assuming that Moore's analysans was consistent with the following two ideas: 's could have done $A$ only if $S$ had willed to do $A$ ' and ' It is not the case that S had willed to do A'.76 While Aune still holds that Chisholm and Lehrer merely begged the question, he no longer considers the idea of question begging to be a sufficiently clear notion to provide a decisive criticism. While I disagree with Aune's original criticism, I shall prescind from it, for I am far more interested in his present criticism; and it is this criticism which brings 
into question the methods of traditional philosophical àrgumentation.

His present criticism is this: "the decisive and instructive shortcomings of Chisholm's and Lehrer's arguments lie in their claims to be refutations, (that is, disproofs) of something." 77 In considering the nature of a strict philosophical proof Aune states that "if, unlike Descartes and spinoza, we think there are no material philosophical axioms, we might want to say that proofs cannot be given in philosophy."78

It seems that he is referring here to the age old insight into the nature of a philosophical proof which Aristotle discusses in both his Topics 79 and his Posterior Analytics 80 . It is simply this: if we are to accept only those premises which are deductively proven, then we shall end in an infinite regress of proofs while looking for an absolutely certain first premise.

Aune does however, charitably add that he is "prepared to speak of a proof in a loose sense--one in which 'axiom' is replaced by 'elementary, non-controversial truth'. " 81 But certainly, this "loose proof" is no proof at all, and in laying down his main criticism of the methods of traditional philosophical argumentation, he has set himself up for my main criticism of his paper. However, before proceeding with this criticism, I would like to briefly summarize the remainder of his paper.

After concluding that Chisholm and Lehrer have failed 
to offer a refutation or disproof of G.E. Moore's hypothetical interpretation of freewill, he goes on to point to the meager value which deductively valid nonproofs have. "One is to relate philosophically interesting conclusions to novel information obtained, often, outside of philosophy--in mathematics, physics, computer science, neurology, or economics" and the other is "dialectical: they are used in showing a philosopher what is implied by assumptions that he or she is considering." 82

The rest of his paper amounts to a belittling of the worth of the deductive arguments found throughout the history of philosophy and the proposal of the scientific hypothetico-deductive model as the method best suited for doing philosophy. The following is a brief summary of this method: "some phenomenon or datum is identified as the subject of inquiry, and a hypothesis is constructed to account for it. The hypothesis is then tested by deducing consequences from it." "If a hypothesis is found that, when put to the deductive test, consistently resists refutation, it is deserving of at least provisional acceptance." 83 I think, however, that it is important to modify this claim. He states that a hypothesis which consistently resists refutation is deserving of "at least provisional acceptance," however, using such a method he can truly say that such a hypothesis deserves only at best provisional acceptance. Such is the nature of any knowledge lexcluding the Cogito) which is not based upon apriori, or more 
accurately, necessary truths and those truths which can be validly deduced from them.

However, this is not necessarily a criticism, for I think that Aune is well aware of what philosophy is reduced to if we should accept what he says as true. After all, has not the field of psychology done something extremely similar? During the past century psychology has tried to liberate itself from rationalistic explanations of the human being and has turned instead to science as the method of choice. And what have we witnessed? First of all, in prescinding from the "black box" of the mind, many great scientific "laws" of behavior have been formulated. No one can deny the merits of Skinner's research in the area of behavioristic learning, or the incredible advances in the understanding of the anatomy and physiology of the brain (which has at least demonstrated that the "mind" does not exist in the pineal gland) or again, look at some of the computer models designed to simulate human reasoning. However, while such research sheds great light on many issues concerning man, it does not automatically follow that the human being is simply a slave to the laws of stimulus--response, or that the mind is the brain, or that human reasoning is not far richer and more complex than any computer simulation.

Psychology, in my opinion, has fallen into its greatest errors precisely when it has tried to reduce something which can be known only through a deep intuitive 
analysis to something which can be empirically validated. Such is the case when a study of the nature of love is reduced to the mating habits of primates or to the number of orgasms a person has during a specified period of time. Yet, while we do find such errors occuring, it seems that much of the data of psychology lends itself to scientific study and cannot be known on the basis of insight into necessary essences. Therefore it would be wrong to claim that psychology has completely mismatched method with datum.

In the field of sociology we find the opposite event taking place. Rather than reducing the object of a priori knowledge to the level of the contingent, the non-necessary is treated as if it were the necessary (although it must be said that a given sociologists may not consider morality, for example, to have a necessary nature). If not explicitly, at least implicitly, what is normal is all too often mistakenly equivocated with what is moral. If the vast majority of all teenagers experiment with marijuana before leaving junior high, then it is normal/moral and thus parents must not be overly concerned.

Philosophy must not make the same mistake of mis-matching methods with data. While it is certainly fair to assert that philosophical positions should be tested by deducing consequences from them, and we must take into account all knowledge which is relevant to the issues at 
stake (even if such knowledge is acquired from a dialogue with other fields), it is not fair to reduce a philosophical position gained through insight into necessary and self - evident states of affairs to a hypothesis - a mere educated guess.

And now we have come to my primary criticism of Aune's paper. As will be recalled, his main consideration used to support his criticism of Chisholm's and Lehrer's responses to Moore is that they are not proofs. Even so, he states that "Chisholm or Lehrer might wish to make a case for their conclusions by claiming that their premisses (concerning consistency) are intuitively obvious to them." However, he considers this additional step in their argument "a pretty idle one", for "If a perception of intuitive obviousness carried any weight, it would also accrue to Moore's perception that his analysis is acceptable on its own merits." 84

We find Aune assuming two things in this paper: first that disagreement among philosophers regarding the results of insight invalidates insight as a tool for philosophical knowledge and argumentation, and second, as mentioned earlier, he assumes the truth of the idea that a deductive argument cannot have all of its premisses proven by deductive reasoning lest we be caught in an infinite regress of proofs. For the sake of conciseness, I will refer to this insight discovered by Aristotle as the "law of the infinite regress." 
While it is certainly true that a claim of insight is not very powerful in an argument (because one is at the mercy of the opponent to admit to seeing the truth gained by insight), it does not follow that insight is no longer valuable as a source of knowledge. On the contrary, it is quite necessary, and the fact that there is disagreement regarding claims of knowledge gained through insight in no way serves as evidence of the validity or invalidity of insight as a method of acquiring knowledge; it simply necessitates the use of other techniques in conveying truths gained through insight. Later in this essay I will explore some of these techniques and point to their usefulness and their shortcomings.

As for his second assumption, it seems that he offers the law of the infinite regress of deductive proofs as something which is intuitively obvious. And if I am correct in asserting this, then it seems that he has little reason to question the validity of the knowledge gained through insight and the deductive method of argumentation can once again be used to construct logically rigorous proofs. As a consequence, I claim that his hypothetico-deductive method does not exclude the traditional method, and further, I believe it can be demonstrated that it presupposes the traditional method in its epistemological justification.

It seems to me, that based upon what he has stated in his paper, he can respond to this charge in two ways: he might claim to be using the law of the infinite regress 
simply as an "elementary, non-controversial truth", or he might propose that this law is known through the use of the hypothetico-deductive method. Yet it seems clear that neither of these responses could ever do justice to the kind of knowledge we possess in the law of the infinite regress.

I claim that the law of the infinite regress is an absolutely necessary truth. It could not be otherwise. And it is precisely this feature which allows us to gain an insight into the nature of a deductive argument. We need not look at many different arguments over a long period of time in order to see this truth. It is not a hypothesis which has simply resisted refutation throughout history. It is not something which has reached the level of a scientific inductive law simply because we have noticed that it has just happened to hold true of every concrete example of a deductive argument. This is an interesting feature which is common to all genuine philosophical insights.

Even if we prescind from the actual existence of any given deductive argument, we are still able to see that for any and all deductive arguments the law of the infinite regress must hold true. Husserl's notion of epoche made reference to this feature of a genuine insight which allows us to "bracket" the actual existence of the object under consideration, without invalidating what is known about the object. 
Notice, I say all genuine insights. I am forced to say this because I do not hold that it is possible to gain an insight into the essence of chair. This I would contend, is because the chair lacks a necessary unity.

The fact that a chair possesses a meaningful unity allows us to recognize it for what it is. However, there is no one feature of a chair which could not be otherwise, that is, every individual feature of a chair could be thought of as changed without a change occuring in the other features. But in the case of a necessary unity, for example, a square, perfect justice, or the nature of a deductive argument, we find certain properties or meaningful relations among their parts which could not be otherwise. That is, if the object were to concretely exist, these things must hold true in every particular exemplification of it. It seems that Plato himself began to see the aforementioned distinction in the Parmenides where he questions the existence of a form for mud, which at best possesses a meaningful unity, and most certainly not a necessary one.

It seems clear that the nature of a deductive argument is more like the nature of a square, which is rich in necessity and capable of being grasped intuitively, than the nature of a chair, which seems to reveal itself only thru time, as we enounter more and more actually existing chairs.

The question still remains as to how one is supposed 
to convey the knowledge gained through insight to another while engaged in philosophical argumentation. I think that there exist at least three common "verbal helps" which can facilitate insight, and while a fair presentation of these methods is beyond the scope of this paper, I would like to briefly mention what they are. 85

The first would be to distinguish the essence under consideration from similar things by giving concrete examples. An example of this would be distinguishing the moral responsibility resulting from manslaughter from the moral responsibility which arises from the act of murder. A second "verbal help" is to give "so-called" definitions. I say "so called" because any definition of something which cannot be reduced to something else will always be circular. However, it may help facilitate the grasping of the nature of an abject. An example of this would be defining a 'positive value' as "that property of an object on account of which its existence is intrinsically better than its non-existence." However, while this definition may be helpful, it is circular because the term 'intrinsically better' clearly implies a positive value judgement.

Finally, one can point out consequences that the insight has which are actually accepted by the other person. An example is found when two people agree that the definiens and the definiendum of a definition must both hold true or both hold false when applied to a given 
situation. It then seoms fair that if a person can demonstrate that this is not the case with the definition in question, then that definition is not a good one.

It seems to me that the nature of both freedom and what it means to be determined can be known through insight. Even while prescinding from the actual existence of individual manifistations of freedom and being determined, we can see that the two essences are necessarily incompatible. However, the proponents of soft determinism obviously do not share this insight. Thus, when dealing with them one is forced to use some other technique to demonstrate what is given by insight.

I think that Chisholm and Lehrer have given excellent examples of how this can be done using what I have mentioned as the third "verbal help". However, Aune would say that they beg the question in claiming that their suppositions are consistent with Moore's analysans but not his analysandum. In response to Aune one could say that there are two senses of "being presupposed", and only one of them involves "begging the question." Fritz Wenisch has reminded of the distinction between presupposing something in the order of knowledge and presupposing something in the order of being. To include among the premisses what is contained in the conclusion is to presuppose something in the order of knowledge, and this truly is begging the question. This Chisholm and Lehrer do not do. However, something can also be presupposed in the order of being, 
meaning that it must be the case. "In general, whenever an attempt is made to establish that something is the case, what one wishes to establish is presupposed in the sense that it actually must be the case prior to the commencement of the attempt to establish it; otherwise, it would be impossible for the attempt to be successful. There is, however, absolutely no logical difficulty connected with this fact." 86

It appears to me that, rather than proposing a new method for philosophical argumentation, our time would be better spent doing an analysis of necessary essences. I realize that this presupposes, (in the order of being), the existence of essences, however, it seems that even Aune, perhaps unknowingly, has presented us with an example in which we have gained absolutely certain knowledge of the nature of at least one essence - namely the essence of a deductive proof. 
B. CONCERNING BRENTANO'S REISM

I would now like to look at Brentano's reism, a view of reality which excludes the existence of all universals, both meaningful unities and necessary essences. This critique of Brentano's reism becomes especially relevant to phenomenological realism when one considers the fact that in his early years, Brentano presented us with many of the ideas which 'prepared the soil', so to speak, for phenomenology (e.g. the notion of intentionality).

Referring to Brentano's turn from an extreme realism to reism, Chisholm states that, "After 1905, Brentano held that, strictly speaking, the only entities that we are capable of thinking of are individuals." 87 These individual things he calls entia realia and included under this heading are such things as "Dogs, red things, squares, unicorns and mermaids." Before 1905, it seems that in addition to these entia realia Brentano included in his ontology entia irrealia. He would include as entia irrealia "privations, possibilities, mental entities, concepts, properties, states of affairs, and propositions." 88 It is interesting to note that Chisholm lists red things, squares, unicorns and mermaids in Brentano's class of entia realia. Clearly, Brentano did not translate entia realia as 'actual or real thing'. Chisholm suggests that we translate ens reale as "individual", "concretum" or "thing" and ens irreale as "nonindividual", "nonconcretum" or "nonthing".89 
Now before proceeding any further, and in order to be fair to Brentano, I must make clear a few things. It seems that when Brentano was a realist, he was an Aristotelian and while I am myself a realist, I am not an Aristotelian. I am far more Platonic in my outlook and this will be reflected in my understanding of Brentano both before 1905 and after. I see this as important in two ways and unimportant in another. I do not see this as being pertinent in the sense that I will be unobjective and biased. I say this because my criticisms should be taken at face value, if they are true, then they are true and if unjustified or false, then they are unjustified or false, not biased. However, the fact that I am Platonically orientated is pertinent in two senses: (1) I am not very familiar with Brentano's earlier Aristotelianism and (2) I have had a hard time metaphysically imagining what Brentano's reistic world would be like - although I do think I have some idea of this. Because of these two factors, I have relied heavily on Chisholm's interpretation of Brentano, which is probably a very accurate and sound one. However, while I am almost apologetic about my ignorance of Aristotle and B̈rentano I do not apologize for my criticisms of Brentano's reism as I understand it, for as I understand it there are a fow real problems. I will use the following three questions as a guide throughout my evalution of reism: (1) Is Brentano's reism ontologically compatible with his notion of intrinsic 
value?; (2) Is Brentano's reism epistemologically compatible with the way in which he uses language?; and (3) Does reality present itself in such a way that would make reism plausible or necessary, or rather, does it present itself in such a way which would allow us to speak of universal properties?

\section{(1) IS BRENTANO'S REISM ONTOLOGICALLY COMPATIBLE WITH HIS} NOTION OF INTRINSIC VALUE?

Let me begin this discussion by saying that I believe we are indebted to Brentano for many great 'insights' into the nature of intrinsic value and its relation to the person. While I disagree with his apparent identification of emotions and volitions I do agree with this view of his: emotional evaluations are to be judged objectively in a way analogous to rational judgements. This view may seem odd to some, however, if one views certain objects as possessing goodness in and of themselves, then it may be correct to love such objects, and similarly, if one views certain objects as being bad in and of themselves, then it may be incorrect to love such objects. Now then, one might object that emotions are not within the full control of the will and therefore are amoral, that is they should not be spoken of as correct and incorrect. I have two things to say in response. Firstly, I do not think that Brentano uses the terms correct and incorrect in a moral sense, but rather in a sense analogous to judgements of the intellect. Secondly, 
as pointed out in chapter four, von Hildebrand, who does not identify emotions with volitions, speaks of two kinds of freedom which we have with regards to emotions: (a) an indirect freedom which is demonstrated in the psychological phenomenon of a person slowly changing his or her character such that more appropriate emotional responses can be given and (b) cooperative freedom through which we can either sanction or disavow individual emotions and thus create a certain "unity" or "distance" between the response and our personal center. 90 seen in this light, the idea of emotional correctness and incorrectness would not be absurd even if we did hold that certain emotional responses, such as feeling disgust towards the act of a grown man beating an innocent child, are morally required.

The questions now arise as to what things are intrinsically valuable? and are these 'things' to be found in a reistic ontology?

In Chisholm's work we are presented with two statements of Brentano's table of values: one formulated by Oskar Kraus and the other Chisholm presents as something which could be drawn "If we follow Brentano." The first list, that is Oskar Kraus' list, includes the following objects as intrinsically good:

every correct judgement and especially every judgement that is evident; every correct emotion and especially every emotion that presents itself as being correct; and also every enrichment of our presentational life.91

The following things are predominantly bad: 
every error; every sensory pain; every unjustified

act of hate--especially every act of hate that is apprehended as being incorrect, thus primarily the hatred of that which is good. Naturally the love of that which is bad is also an evil--especially the love of that which is apprehended as bad.92

What immediately jumps out at me when $I$ read this 1 ist is the blatant ego-centricity of the things both good and bad. This becomes particularly evident when one reads the following passage by Oskar Kraus:

Every conscious act as something that is self-conscious contains inseparably some presentation. Therefore it is essential to every mental act that something valuable be given along with that act. It follows that there is no evil that does not contain some trace of what is good.93

Notice here, he does not say that there is no presentation of evil which does not contain some trace of what is good, but rather "there is no evil which does not contain some trace of what is good." It seems clear that in saying this he is not referring to some kind of Augustinian notion of existence as intrinsically valuable (and therefore all that exists, even evil, is good at least to the extent that it does exist). No, he is not predicating mere existence as being intrinsically good, rather, it seems that he is stating that all intrinsic good or ovil consists in the conscious activity of the subject. I think that apart from any criticisms in connection with his reism, this view can be criticized for failing to do justice to those objects which are intrinsically valuable. After reading Oskar Kraus' list I am left wondering: what about all of the 
objects of judgement, the intentional objects of emotional responses and the content of presentations?

However, this problem is not to be found in Chisholm's own list of things which are intrinsically valuable. He states that:

If we follow Brentano, we may make two lists - a list of things that are intrinsically good and a list of things that are intrinsically bad. The good list would include such items as these: pleasure, happiness, love, knowledge, justice, beauty, proportion, good intention, and the exercise of virtue. The bad list, on the other hand, would include such items as these: displeasure, unhappiness, hatred, ignorance, injustice, ugliness, disharmony, bad intention, and the exercise of vice. 94

Clearly, this list is much closer to what one would expect a list of intrinsically valuable things to look like. However, upon reading this list the following question gains new force: Is Brentano's Reism ontologically compatible with his notion of intrinsic value? After all, this list reads like a review of Plato's favorite essences or forms. Can Brentano speak of "pleasure, happiness, love, knowledge, justice, beauty...the exercise of virtue" etc. and not be committed to universal properties? For that matter, concerning Oskar Kraus' list we can ask, can Brentano exclude mental entities or even more generally, can he exclude universals from his ontology and continue to speak of judgements, emotions and presentations? But let us not get ahead of ourselves.

Concerning his theory of intrinsic value we must ask the following: If only concrete, existing, individual 
things are knowable, then what kind of object does beauty or love become? As stated earlier, after 1905 Brentano no longer included mental entities, concepts, properties, states of affairs, and propositions in his ontology. So wo must ask, What kind of objects are these objects which are intrinsically valuable? Is there any chance that Brentano would claim that in saying love, happiness, and justice are intrinsically valuable, he merely means that individual existing instances of love, happiness and justice are valuable, and nothing apart from these concrete instances of love, happiness and justice exists? If he denies that this is what he means, then it seems that he is committed to universal properties or concepts and must, therefore, abandon his Reism. If this is in fact what he means, then we are lead to our second central question:

\section{(2) IS BRENTANO'S REISM EPISTEMOLOGICALLY COMPATABLE WITH}

\section{THE WAY IN WHICH HE USES LANGUAGE?}

Precisely what we want to ask is this: If the only entities that we are capable of thinking of are individual, concretely existing things, then am I able to speak meaningfully about things like love, happiness or justice? Or for that matter, can one speak of judgements, emotions and presentations in a general fashion, creating rules which seem to cover a whole class of objects without at least creating a universal concept?

Brentano saw that if one holds a reistic view of 
reality then one should not use predicates in language, for predicates claim that a particular object has a certain universal property. Chisholm uses this example:

In saying, "some dogs run" and "A rose is red," we use both terms ("dogs" and "rose") and predicates ("run" and "red"). But we could use only terms and dispense with predicates. For example, instead of saying, "Some dogs run," we could say, "Some dogs are runners"; and instead of saying, "A rose is red," we would say, "A rose is a-red-thing. "95

Chisholm states that the original traditional phrasing of the latter statement seems to relate a flower to the abstact object of redness. However, Brentano's paraphrase combines two individuals, a rose and a-red-thing, and these two things are related to one another through Brentano's modified theory of substance and accident. (We will look more closely at Brentano's theory of substance and accident later on in this paper when we look for ways in which Brentano has tried to avoid some of the problems associated with reism.)

However before asking how Brentano relates these two ir.jividual things we should ask what this means. He has paraphrased "Some dogs run" into "Some dogs are runners". Now, while I grant that the second sentence certainly follows from the first, I will not grant that they are equal in meaning. Not only this, but I would say that the first sentence is more basic than the second. After all, do we say that I run because I am a runner, or rather that I am a runner because I run? I think the latter is true. Thus, I am called a runner only because 'run' can truly be 
predicated of me. Think of how funny it would be if someone asked me "Jim you had been exercising so well during the last month and said that you were feeling much better, so why did you stop running?" and in response I stated that the reason I stopped running was because I ceased to be a runner. I think few people would buy such an answer. However, what if we were to allow Brentano to speak in the way he does? Let us say for a minute that "a rose is a-red-thing" and "some dogs are runners" and at the same time keep in mind that only individual, concretely existing things are knowable to the human mind. Let us put aside all Platonic, Aristotelian and conceptualist notions and try to understand just what it would then mean to say "a rose is a-red-thing". This is indeed a very difficult task. As a matter of fact, I think it is impossible to do. Without the knowledge of what redness is, without at least a concept of red, I have no idea what it means for anything to be a-red-thing. The word 'red' in the term 'a-red-thing' is a completely empty word. Where there once was meaning there is now only a void.

There are only two senses in which there is any meaning to the term 'a-red-thing' and neither are satisfactory. Let us try to picture what would happen in the $\operatorname{cas} \theta$ of someone pointing to a fire truck and saying "There!, that is a-red-thing." I could then attach some meaning to the term 'a-red-thing', that is, I would think of the fire truck. However, if the same person were to 
point to a ripe apple, and then again at the background of a stop sign, and both times say "There!, that too is a-red-thing", then only one of two things could happen. Either I should think that the person is foolish for calling three radically different objects by the same name and thus fall into an extreme nominalism or else I will begin to abstract the property of redness from each of these three objects and form a concept of red, thus escaping from both nominalism and reism. For Brentano, the only choice is an extreme form of nominalism in which we may call many different objects 'a-red-thing' but in reality there is no reason for doing so, it is not done in virtue of some similarity which they share--some property or properties common to them both.

In such an extreme case of nominalism I insist that I cannot know what you mean when you say 'a-red-thing' because you do not use the word 'red' to denote the property redness, rather, for all I know you might be saying that it is a porcupine. And for the reader to understand what I have just said presupposes that he or she knows what I mean by 'porcupine', which in the case of an extreme nominalism might mean ice cream. And ice cream etc. etc.

This leads us to our next question:

(3) DOES REALITY PRESENT ITSELF IN SUCH A WAY THAT WOULD MAKe REISM PLAUSIbLe, OR RATHER, DOES IT PRESENT ITSELF IN 
SUCH A WAY WHICH WOULD ALLOW US TO SPEAK OF UNIVERSAL PROPERTIES?

Perhaps before we try to answer this question, we should take a look at some of the ways in which Brentano has tried to avoid some of the difficulties we have encountered concerning the meaning of words. In doing so we will notice that the two distinct questions, one concerning ontological justification and the other concerning epistemological justification, are not so distinct. In order to focus upon both intrinsic value and language meaning I have tried and will try to keep these questions distinct, but this is not to deny that in reality they are closely related to one another. For these questions point to the intimate relationship between knowledge and its object.

Perhaps the ontological question comes first, for if Brentano can point to some metaphysical objects which justify his speaking in general terms about things, for example his claim that beauty and love are intrinsically valuable, then I would never raise questions concerning the meaning of such claims. However, it is because words like 'beauty,' 'love,' and 'justice' point to universal properties or at least concepts, and because Brentano fails to recognize the existence of these universals, that I must raise the question concerning what he means when he uses such terms.

The first clarification Brentano might make would 
concern the way in which he uses terms like 'beauty,'

'love,' or 'justice.' In the first few pages of Chisholm's book on Brentano and intrinsic value we find the following passage :

Finally, Brentano's theory has a feature that may seem to conflict with what I have called its objectivity. He says that the terms 'good', 'bad', 'better', when used in connection with intrinsic value, are all syncategormatic. In holding this, Brentano is rejecting the simple theories of value predication that were presupposed by G.E. Moore and Max Scheler: The word "good," they seemed to say, has as its intention a simple quality comparable to yellow or blue. 96

By using the term "sycategormatic" Brentano is simply saying that the terms 'good', 'bad', 'better' do not actually refer to any real object. It seems likely that Brentano would say the same thing concerning terms like 'beautiful, ' ' lovely,' or 'just.'

In response to this passage I would like to say two things. The first point is that while Chisholm compares Scheler and Moore's theories of the good to theories which may perhaps seem plausible with regard to colors such as yellow or blue, Brentano's theory would make it necessary for him to reject such a "simplistic" theory of colors as well. And the question remains as to whether reality requires us to reject or support such "simplistic" theories. My second point concerning Brentano's idea of "syncategormatic" terms is that by calling these terms syncategormatic, he only tells us how he is not using them. Thus, Brentano merely pushes back the question as to how he 
actually does use these terms.

A second way in which Brentano has tried to avoid some of the difficulties of reism is through his theory of substance and accident--a theory which, by the way, varies greatly from the traditional Aristotelian concepts of substance and accident.

Chisholm gives the example of a person who sees a tree. "In Brentano's terminology the one who sees a tree is an accident of the one who thinks about a tree, and the one who thinks about a tree is, in turn, an accident of the self or person." 97 Therefore, according to Brentano, accidents may have accidents. An accident which may have another accident is called a substrate, although a substrate need not have other accidents or itself be an accident. The unique case of a substrate which is not itself an accident is called a substance. Further, and again in opposition to Aristotle, he claims that the relation of accident to substance is not that of the accident being a part of or existing in the substance, but rather he claims that the substance is a part of the accident. Thus Chisholm concludes that "Using the terminology of 'part' and 'whole', we may say that, according to Brentano, a substance is a thing that can be a proper part but cannot have a proper part; an accident is a thing that has a substance as a proper part." 98

Now the following shall make clear how he wants to use this theory of substance and accident in order to avoid 
some of the difficulties associated with reism:

Every substance and every accident is an ens reale, according to Brentano. He also says, in effect, that every heap, or aggregate, of entia realia is itself an ens reale. Such considerations, he thinks, remove the apparent need for supposing that individual things are related to abstract objects. Individual things are related only to other individual things.99

The key to Brentano's proposed solution to the problem of apparent predication (which arises from his reism) lies in his allowing heaps or aggregates of entia realia to be entia realia. As Chisholm has stated, Brentano thinks that this will remove the apparent need for relating individual things to abstract objects, namely properties or concepts. The only way in which I can see him viewing this as a solution would be if he were to group only those things which have traditionally been said to share a common property, for example, my group of 'red-things' - the fire truck, the red apple and the background of a stop sign, and claim that all of these taken as a group are to be considered as ens realia. If he were to create an aggregate of things which have never been viewed as sharing a common property then this theory does no work for him, for what he wants is to relate individual objects not to properties but to individual things, namely aggregates, but this would appear to work only if the aggregate is composed of objects which have in the past been seen as sharing a common property.

Assuming the existence of such an aggregate, he could 
say that it is this aggregate of individual, concretely, existing things which he calls intrinsically valuable. For example, it might be that all of the concretely existing beautiful-things should be taken together to form an aggregate and thus earn the title of entia realia. Thus, when he would call beauty intrinsically valuable he would merely be referring to this 'individual' aggregate.

However, this has two consequences which may be problematic.

First of all, he could no longer speak of such terms as being syncategormatic, for they refer to a really existing object, namely the aggregate. However, it is questionable as to whether he would speak of beauty as intrinsically valuable rather than all beautiful-things. While Chisholm does say that "If we follow Brentano" we may include beauty in the list of intrinsically good things, it is not clear as to whether or not this phrasing would be true to Brentano only during his earlier period of thinking. However, this criticism would at least hold true of what he did state about terms like good, bad and better. So we find at least some confusion here concerning how he hopes to avoid the problem of apparent predication. On the one hand he wants to say that the terms (good, bad, better) do not refer to any really existing thing, and this he does by calling them syncategormatic terms, and on the other hand he wants to say that individual things are related to individual things, namely aggregates of those things. 
The second problem concerning this theory of substances, accidents, and aggregates is somewhat more central to my criticism of reism. The problem is this: In virtue of what does he classify a given number of these individual, concretely existing things as belonging to the same aggregate? As we have seen earlier, aggregates could only begin to get around predication if the members composing an individual aggregate were things which were traditionally said to possess a common property. In the past we would have said that this shared property was predicated of the individual concrete things. Brentano thinks that we are now merely relating the individual concrete thing to another concrete thing, namely the aggregate. However, this does nothing to solve the problem of reism, it merely pushes it back even further.

We are justified in wanting to know why he would say that all red-things belong in the same aggregate. Is it because they are identical? Certainly not. Brentano of all people, being a meriological essentialist, would reject this. Time and spacial location would suffice to disprove this notion. Is it because they are similar? Similar in what respect? The similarity certainly could not be that they share a common property.

I can think of no reason why he would include these things in the same aggregate. If they are then grouped together haphazardly, then there is no reason why I should want to relate the individual concrete red-thing to an 
aggregate of red-things, for they share absolutely nothing in common.

Is this the way it must be? Must we try to avoid properties at all costs? I think the answer is no. In what follows I will briefly try to show the reader why I think Brentano would have been justified had he included properties in his ontology. In order to do so we shall investigate the nature of two things which Brentano spoke of as entia realia, that is, we will look at two things which he did include in his ontology and see if we can arrive at the existence of universal properties. These two objects are red things and squares.

However, before trying to arrive at universal properties, it may be best to look at what is perhaps a less controversial solution to reism, namely conceptualism. I am convinced that if a person will grant me the real existence of red things and squares then $I$ can at least force a choice between an extreme and meaningless nominalism and conceptualism (and I believe that even conceptualism will necessarily lead to either an extreme nominalism or a theory of universal properties.)

As stated earlier, I think that if someone were to take me around and point first to a fire truck, then later at a ripe apple, and then again at the background of a stop sign, and each time say to me - "There, that is a red thing", then eventually I think one of two things would happen. Either I would think the person an idiot for 
calling three radically different things by the same name (and acting as if there were something represented by the name), or else I would eventually abstract from each of these their common property and form a concept of redness (and I would then associate the word 'red' with this concept). I think that it is much more likely that the latter should happen. It is not the case that the two responses on my part are equally justified. If I were to fall into an extreme nominalism after such an experience, then it would be because I have failed to see something which really was there. Conceptualism, however, is justified by my experience of the three objects. Each of these three objects present themselves as having something in common. They share the color red. I can come to know this color and its name by associating the presentation of red with the name 'red'. Thus, through similar experiences of red objects I both expand and refine my concept of red and its various shades.

But I am forced out of conceptualism through the following question: In virtue of what have I developed my concept of red? Is it not in virtue of seeing the property of redness? One might think this absurd and propose that rather than seeing the property of redness I have merely seen red objects. But I ask again, "in virtue of what are these objects called red?" Thus one is forced again to look at an extreme nominalism which answers, "In virtue of nothing is this object called red, and there is no reason 
for calling all 'red' objects by the same name for they share no common property." The only other alternative is a theory which involves universal properties. A theory which allows us to say, it is in virtue of the fact that all of these objects possess some degree of redness that they are all called red. (It is interesting to note that one presentation of red is sufficient for me to know the color red. Perhaps it would take a few presentations of red while being told its name before I would know the color by that name, however, it is not the case that I must see red more than once in order to know it as such. Abstraction may, however, still have its place when we consider that we are seldom presented with red as such, but rather with objects that possess red accidentally.)

A further feature which points to universal properties is the fact that with regard to objects such as red things and squares we find a necessity which could not be known through inductive generalization. For example, the statement that "orange lies in between yellow and red in the order of similarity" is necessarily true. It is in virtue of the very nature of the objects of yellow, orange and red that this hold true. It is not something to which one says that "thus far in every instance that persons have encountered these three colors, orange has as a matter of fact fallen between yellow and red in the order of similarity." It is not merely a matter of fact, it is necessarily the case. Anyone who denies this has failed to 
properly see the nature of these three colors.

This feature of necessity cannot be accounted for or done justice by conceptualistic views or even by Aristotelian views of universal properties. For in the Aristotelian view, there is no property which exists apart from the particulars and thus there is no reason why all of the particulars must necessarily possess certain identical features. I do not deny that the Aristotelian view of being may hold true with regards to certain objects. Such would be the case concerning a table. I have witnessed cumbersome discussions during which persons have tried to find a feature of a table which would necessarily hold of every table and at the same time not force us to include floors, shelves or animals in our concept of table. I think it is a futile excercise, for while there is something meaningful about the term 'table,' there is no one feature of a table in virtue of which it is a table or put another way around, there is no one feature of a table which could not be otherwise; that is every individual feature of a table could be thought of as changed without a change occuring in the other features. But this cannot be said of redness, for you could never show me one instance of redness which did not meet the criteria of being one of two boundaries of orange in the order of similarity. If you showed me such a color we would not be correct in calling it red.

The same holds true of squares. Brentano has granted that squares are real things. However, he will not grant 
that there exists a property of squareness. I should say quite the opposite: I am not certain that I have ever seen a geometrical figure which had four perfectly equal sides which met one another at precisely right angles. However, I will claim that necessarily, if such a figure were to exist, its diagnals would be of exactly equal length. Further, this necessity is not a result of the subject containing the predicate, it is not a mere tautology whose truth depends upon the way I have defined a square. I need not, and perhaps should not speak of a square (for my concept of square may contain many ideas), but merely a figure with four sides of equal length and which meet at right angles. Now when I recognize the fact that the diagnals of such a figure must necessarily be of equal length, I come to know something both necessary and informative, not merely tautological, for the notion of diagnals of equal length is not contained in the notion of a figure with four sides of equal length which meet at right angles.

How is such knowledge to be explained? It seems that the best answer is found in the view that there exist ideal essences, essences which exists regardless of whether or not any particulars exemplify them. This is the view of reality which I think is justified by reality itself, a view which was embraced by both Plato and the many of the early phenomenologist.

Ultimately, Brentano's reism fails to explain why we 
can speak of certain objects as being intrinsically valuable, for it denies the existence of these objects in the only form of existence which would justify his claims. Further, it renders all language unintelligible, for there are no real features or properties in virtue of which I call a given class of things by the same name. This leads not only to an arbitrariness of language but to complete meaninglessness. And lastly, reism fails to do justice to the given, to the necessary features of certain highly intelligible objects such as the essence Red and the essence of Square. 


\section{c. THE THIRD MAN ARGUMENT}

I would now like to take a look at the third man argument (TMA) as found in the Parmenides. This argument is perhaps the most famous argument against the existence of Platonic Forms, and curiously enough, it is Plato who first introduces the argument. I will briefly review the argument and then look at what a few modern writers have had to say about it. My response to the TMA leaves open a number of questions (particularly with regards to the nature of participation), however, the intent of this response is merely to familiarize the reader with the TMA and show where it fails.

Recent literature seems to focus upon two main questions: (1) Are these arguments destructive to Plato's theory of Forms? and (2) Did Plato think they were destructive? These questions will guide the following discussion; however, in addition to these I think it is fair to ask two further questions: (1) If these arguments are destructive of the theory of Forms, how, if possible, can the theory of Forms be modified to avoid the difficulties? and (2) Is Plato correct in his e' lluation of the arguments?

Recent debate concerning these questions begins with G. Vlastos'(1954) "The Third Man Argument in the Parmenides". While this is the article which started a whole stream of literature flowing, I much prefer the presentation of the argument found in his 1969 article 
entitled "Plato's 'Third Man' Argument (Parm. 132A1-B2): Text and Logic." Although, I will begin with this text I will later return to his 1954 article in order to investigate the ontology involved in the TMA and also for speculation concerning Plato's state of mind with regards to the arguments. Apart from the text itself, I will be using Vlastos' two articles (almost exclusively) as the basic framework for this discussion. There are two reasons for this: I think his interpretation is generally true to what Plato has written; and he clearly and concisely exposes both the logic and the necessary assumptions of the argument (some of which are only implicitly stated in the text; therefore his being true to Plato's text is doubly important). In the end I shall evaluate both Vlastos' and Plato's treatment of the argument and offer my own proposed solution to the problem: one which I think avoids the regress and can be textually defended.

I must admit that had anyone other than Plato raised the "Third Man Objection" to the theory of Forms I should have dismissed it with little thought, for it does not seem to me a very good argument. However, Plato does in fact present us with this argument, an argument which appears to destroy the theory which he has most fervently defended in earlier dialogues, and he does so without even the slightest attempt to refute the argument. This is indeed fascinating. Let us take a look at the text and see what sets the stage for the TMA. 
The Parmenides has one of the most difficult settings to recount. It is narrated by cephalus of Clazomenae, who along with some fellow countrymen, journeyed to Athens. Upon arriving in Athens, Cephalus finds his friend Adeimantus, whose half-brother Antiphon lives nearby and can tell the story of the great discussion and arguments between Socrates, Zeno, and Parmenides. It seems that Antiphon himself learned the story from Pythodorus who was a companion of Zeno and a witness of the event. So what we have is Plato, writing a 'dialogue' in which Cephalus narrates a story learned from Antiphon who himself only heard it from Pythodorus who actually witnessed the occurence. This is certainly an interesting setting.

One other background note perhaps worth mentioning is the fact that according to the story, Parmenides was quite grey and distinguished looking, perhaps sixty-five, Zeno, his favorite companion, was about forty, and Socrates was then quite young.

This point may perhaps be insignificant, but I think that it could be interpreted as significant in two different ways. Plato has removed this story as far as possible from himself. Also, he has portrayed socrates as being quite young. It is possible that Plato has at all costs tried to avoid making socrates, his teacher, look unduly bad. His error can be blamed on youth, and further this story is recounted only through a long chain of 
persons. Thus, the first interpretation would be that plato has intentionally tried to avoid the scenerio of his great teacher in old age being presented with arguments which would appear to undo much of his life's work.

However, a second, and admittedly less probable explanation would be the following: If we suppose that Plato would like us to take the chronology found in this dialogue seriously, then it would hold true that socrates continued to teach and defend the theory of forms long after his discussion with Parmenides. Thus, it could be Plato's way of stating that he did not consider the argument to be destructive to the theory.

The third man argument in the Parmenides takes two forms. The first version of the argument is commonly referred to as the Largeness Regress (132a-b) and the second version deals with a regress of Ideas as Paradigms (132d-133a). Because of the brevity of this paper I would like to focus upon only the first of the two versions. Little will be lost, for the logic and analysis of the first will, with minor alterations, hold true of the second version as well and neither of the arguments present a unique problem, but rather, they present the same problem in two different ways.

I will give the first version of the argument in three quotes: Q.A; O.B; and Q.C. Thus, the reader can easily be referred to the corresponding sections of text when we begin to formally analyze the argument. 
Parmenides sets up the problem as he sees it in this way :

Q.A: I suppose you think that each character is one for some reason as this: when some plurality of things seem to you to be large, there perhaps seems to be some one characteristic that is the same when you look over them all, whence you believe that the large is one. 100

Socrates of course agrees with this. After all, what Parmenides has suggested merely points to what has been explictly stated in many of Plato's middle dialogues, namely, that there exist forms or ideal essences for things like beauty, goodness, the equal and so forth. However, Parmenides quickly moves on to something which it seems Socrates has never considered before.

Q.B: What about the large itself and the other larges? If with your mind you should look over them all in like manner, will not some one large again appear, by which they all appear to be large?101

This is the crucial part of the argument. Parmenides has just asserted that in using socrates' criterion for formulating the existence of an ideal character, another character just like it must necessarily come into existence. This section of the argument is going to be the focus of our analysis, for socrates has granted to Parmenides that what is asserted seems to be the case and although Parmenides has not yet pointed to an infinite regress, the regress has already begun. Beginning with the existence of one Form, Parmenides has arrived at the existence of two forms. However, let us allow Parmenides to draw out the conclusion himself: 
Q.C: Therefore, another character of largeness will have made its appearance alongside largeness itself and the things that have a share of it; and over and above all those, again, a different one, by which they will all be large. And each of the characters will no longer be one for you, but unlimited in multitude. 102

The three quotes, Q.A, Q.B, and Q.C, taken together comprise the famous third man argument. It is a suprisingly short argument and extemely astonishing, for socrates objects to neither the premises nor the conclusion even though the argument appears to destroy his theory of Forms. However, there is more to the argument than meets the eye, and perhaps after looking at Vlastos' analysis of the argument we will have a better idea of why socrates might agree that an infinite regress would follow from his theory of Forms. Then we will judge for ourselves.

Vlastos (1969) has aimed at stripping the argument bare of all rhetorical and stylistic garnishings in order to expose the basic premises. The first step, however, is to present the theory which is under attack. The theory of Forms could be stated as follows:

1. If any set of things share a given character then there exists a unique form corresponding to that character; and each of these things has that character by participating in the Form. 103

This is the theory which Parmenides attributes to Socrates and Socrates agrees that this is in fact how he views reality. A formal representation of this would be: Given that:

1a) $a, b$, and c are F, (that is, there is a set of particulars $a, b, c, a l l$ of which participate in a 
common character $F$ ),

it follows that,

1b) There exists a unique Form (which we may

call'F-ness') corresponding to the character, $F$, and $a, b, c$ are $F$ by participating in F-ness.

Part 1 corresponds with the part of the text which I presented as Q.A. Vlastos now moves on to formulate the crucial part of the argument which is found in $Q . B$.

Remember that it is in this section that Parmenides begins the regress.

2. If $a, b, c$, and $F$-ness are $F$, then there exists $a$ unique Form (which we may call "F-ness2")

corresponding to $F$, but not identical with F-ness;

and $a, b, c$, and $F$-ness are $F$ by participating in

F-ness2.104

Now Vlastos argues that in order for Socrates to agree with this hypothetical statement he must be assuming something which is not made explicit in the argument.

"Socrates must be assuming what I have called

'self-predication,'

$S P=$ The Form corresponding to a given character itself has that character." 105

Given SP, 1a, and 1b, it follows that:

2a. $a, b, c$, and F-ness are F

Thus we have the antecedent to 2 . However, the consequent still does not follow. That is, even if we were to say that the Form of a character itself possessed that character, why should it be necessary to posit the existence of a second Form? Vlastos argues, and I think correctly, that socrates must be making a further 
assumption which he calls Non-Identity (NI).

"NI = If anything has a given character by participating in a Form, it is not identical with that Form." 106

It is only with this second tacit assumption that Socrates must be committed to the existence of an F-ness 2 .

Thus, given $1,2 a$, and NI, we necessarily arrive at:

"2b There exists a unique Form (which wo may call $F$-ness 2), corresponding to $F$, but not identical with F-ness; and $a, b, c$, and $F$-ness are $F$ by participating in F-ness2."107

What follows in Q.C. is merely a repetition of what has happened above. If we take $a, b, c, F-n e s s$, and F-ness 2 together we will recognize that they also share the same character. This, taken together with the principle of Non-Identity, leads us to posit the existence of yet another Form, F-ness3. And the same can be done with F-ness 3 and F-ness4, and so forth. Thus Parmenides has used the Third Man Argument to arrive at an infinite regress of Forms. In Parmenides' own words "If only one, then many. " 108

Now that we have seen the argument both in its textual form and in a more formalized form I think we can try to judge whether or not it is actually destructive to the theory of Forms. Of course, if we find that the argument is invalid or unsound then we will not consider it destructive to the theory.

It seoms clear that the most questionable premise of the whole argument is the Non-Identity assumption. Without 
NI, Parmenides would be unable to derive the consequent of

2 and would therefore not have been able to start the regress.

Not only is NI going to lead to undesirable consequences for Plato but in addition to this it is quite inconsistent with the two other premises denoted as 1 and SP. Both Sellars and Strang have noted this and it can easily be shown:

If,

1. If $a, b, c$, are $F$ then there exists $F$-ness (a form which corresponds to $F$, and $a, b, c$ are $F$ by participating in F-ness.)

and,

$$
S P=F \text {-ness has the character } F
$$

then we could hardly say that,

$N I=$ If anything is $F$ by participating in a Form, it is not identical with that Form.

For it would then follow that

F-ness $=l=$ F-ness. 109

Now concerning the fact that $1, S P$ and $N I$ form an inconsistent triad, vlastos is in agreement with sellars and strang. However, this is where they part.

Perhaps we should begin with the sellars-strang analysis. While sellars and strang have written independently they have both said the following in different ways. Namely, that once we have realized that 1 , SP, and NI form an inconsistent triad we can easily correct the argument so that it works as a valid argument. 
Specifically, all we need to do" it substitute "a unique

Form" in 1 with "at least one Form". Thus, 1 becomes:

"1'. If a number of things share a given character, then there exists at least one Form corresponding to that character; and each of those things has that character by participating in that form." 110

Now there is no doubt that this would create an internally consistent argument, however, vlastos asks the key question: would it be the one in the text, the one we are supposed to be analyzing? In response he answers No, and again I would have to agree with him. All we have to do is return to Q.A. and see how the argument is begun in order to realize that socrates held that there exists one Form and only one Form. Vlastos defends this view by making reference to many other passages of Plato as well: the Republic 476a, 507b, 596a; Parmenides 131a8-9, 132b5, and $132 \mathrm{c} 3-4$. It seems fair to say that while the Sellars-strang interpretation of the argument would yield an internally consistent argument, it is not this same argument we find in the Parmenides nor is it one that Plato would be likely to formulate elsewhere.

I would like to step back in time and take a look at what conclusions vlastos came to in 1954 concerning the crucial point of argument. Vlastos has argued that rather than the full-strength Non-Identity assumption, Plato could have asserted a modifided version of NI which I will call NI'.

$N I^{\prime}=$ "If any particular has a certain character, then it cannot be identical with the form in virtue of which we apprehend that character. If $x$ is $F, x$ 
cannot be identical with F-ness when, and only when, the values for $x$ are particulars, $a, b, c \ldots 111$

This seems to me to be an obvious solution to the problem. Why is it that socrates did not object to Parmenides by making explicit that this is all that is assumed? Vlastos' response to this is interesting. Vlastos asserts that Plato, at the time of writing the Parmenides, was in a state of honest perplexity. Quite frankly Plato was baffled by this argument. Why?

Vlastos tries to show why he thinks this is the case and in doing so he investigates the question as to whether Plato's theory of Forms entails the two tacit assumptions, (SP and NI), which are necessary to produce the infinite regress. Two further ideas which are found throughout the writings of Plato must now be made explicit. The first is the Doctrine of Separation. In the Parmenides at 130b, we find the following: "Tell me, Socrates, have you yourself drawn this division you speak of: on the one hand, certain Forms separately by themselves and, on the other, separately, the things which partake of them?" This separation of the Form from its particulars is a key idea and sheds some light on the problem of forms.

The second idea which must be made explicit is Plato's notion of being. Vlastos states that for Plato, to say ' $x$ is', in the strict sense of is, entails that:
i) $x$ is intelligible
ii) $x$ is changeless 
iii) $x$ is not qualified by contrary predicates

iv) $x$ is itself the perfect instance of the property of relation which the word for ' $x$ ' connotes.

Pertaining to this notion of being, the following point must be made. We clearly see that (iv), the idea that the Form is the perfect exemplication of the property, pressupposes the notion of Self-Predication. So, if Vlastos is correct, Plato's very notion of being entails SP.

Concerning Vlastos' Doctrine of Separation, the following two points must be made: First, forms are separated from particulars in that forms have a higher degree of being and reality. This notion is referred to as Plato's Degree of Reality Theory. Vlastos quotes the Republic when he states that according to Plato particulars are 'between the purely real and the totally unreal.'

The second point concerning the separation theory is that, if Vlastos is correct in holding that the separation of Forms from particulars occurs due to the Degree of Reality theory, then I think Plato failed to recognize the distinction between differences in degree of reality between beings of the same kind, and differences in kind of being. That is, according to Vlastos' interpretation of Plato, the Separation which exists between forms and particulars is due strictly to a difference in degree of being and not in kind of being, but I would suggest that Forms and particulars possess different kinds of being. Vlastos tries to use this notion of Degrees of Reality 
to demonstrate why he thinks Plato is going to be committed to the assumption of Non-Identity.

For if the Form, Largeness, is superlatively large, while large mountains, oaks, etc., are only deficiently large, it must follow that the single word, 'large', stands for two distinct predicates: a) the predicate which attaches to the large particulars; b) the predicate which attaches to Largeness. Call a) 'large' and b) 'large1'. Now since Largeness is, by hypothesis, the Form of the predicate 'large', it cannot be the Form of the different predicate 'large1'. There must then be two Forms, Largeness and Largeness 1 and the full-strength form of the Non-Identity Assumption becomes unavoidable: not only can no large particular be identical with the form, Largeness, in virtue of which it is seen as large, but Largeness itself cannot be identical with the form, Largeness 1, in virtue of which we see that it is Large. 112

Now I would like to make clear just what vlastos is saying and then show where I think Vlastos has made a mistake in drawing the conclusion that NI follows from such assumptions. What he is basically saying is this:

Given the following three ideas:

1) the Form is separated from its particulars (Separation),

2) this seperation is due to a difference in degree of being rather than a difference in kind of being (Degrees of Reality Theory), and

3) there is a Form, F-ness, which is to a high degree $F$, while the particulars $a, b$, etc. are to a lesser degree $f$

then it must follow that, the single word, 'F', stands for two distict predicates: a) ' $F$ ' for the $F$ particulars and b) 'F1' for F-ness which is itself highly F. Now since F-ness is the form of the predicate 'F', it cannot be the form of the different predicate 'FI'. There must then be two forms, 
F-ness and F-ness1, and the full-strength version of the Non-Identity Assumption becomes unavoidable.

Now he states that it is "the same reasoning which compelled the 'separation' of any F particular from its corresponding Form, F-ness, (that) also compels the 'separation' of any Form from itself, and splits off F-ness from F-ness1." But this is not necessarily the case. Vlastos, I think, rightly sees that Plato erred in separating the Form from the particulars in the way in which he did. That is, Plato was correct when he saw that the Form of a property should be separated from the particulars which exemplify the property, but he erred in separating them based upon a difference of Degrees of Reality rather than upon their real difference in kind of existence.

That they differ in being is seen by the fact that we know the particulars through empirical means but we know the Forms through their intelligibility. However, we do not want to point to a difference in kind concerning the property predicated, for we predicate of both the form and the particulars some degree of participation in the necessary features of the property; the form is the essence of the property, whereas the particulars participate in the property only to a greater or lesser degree.

So we can say this: Plato was justified in seperating the Form from the particulars. Further, this seperation is 
central to his theory of Forms and it is explicitly found in his texts. However, a separation should not have occured due to a difference of degree it should have happened due to a difference of kind.

It certainly is understandable that Vlastos would assume that with regard to another difference of degree, this time the degree to which an object exemplifies a property, Plato would also make a separation. However, I would argue that it is highly unlikely that Plato would make the same mistake here. Firstly, Plato confused his justification for making a separation with regards to Forms and particulars - but he was justified. With regards to the separation of a property from itself he is not justified. It is not a matter of doing a justifiable act for the wrong reason, it is not a justifiable act. Second, if the degree to which an object exemplifies a given property were sufficient reason for creating a separation, then this separation would result in an infinite regress not only of the Form, but there would also exist as many properties to be predicated as the various particulars which exemplify the property to differing degrees. That is, in the example Vlastos gave concerning Largeness, not only would there exist a seperate property 'Large' and 'Large1', one for the particulars and one for the Form Largeness, but there would also exist a seperate property for both the large mountain and the large oak for they differ in degrees of largeness. Plato would not make this mistake. 
It seems that vlastos has done us a great service in exposing the logic of the argument, the two hidden assumptions (SP and NI), and the metaphysical theories which lie in the background of the argument. However, I do not think he has convincingly shown us how Plato, whether knowingly or unknowly, was committed to the theory of Non-Identity.

Thus, it is still a mystery as to why he did apparently allow the Non-Identity assumption to be used. For with Vlastos I wholly agree that Non-Identity a necessary assumption if the argument is to lead to a regress, and further, that the NI assumption could easily have been modified to exclude the Non-Identity of a Form with itself. Where we disagree is whether or not some of Plato's other ideas account for an 'unconscious' and unstated commitment to, and acceptance of the Non-Identity as sumption.

Vlastos has argued that Plato was in an honest state of perplexity because he was not explicitly aware of his own assumptions, which is possible considering the complexity of the assumptions and the diverse metaphysical implications of these assumptions, (and Plato never did explicitly state some of the most important assumptions). I will not argue either for or against this, only Plato himself can decisively settle the issue. Thus, I myself am still in an honest state of perplexity with regards to how Plato viewed the argument. 
However, before concluding, I would like to state in my own words what I thought about the TMA before reading Vlastos' articles and what I still think to this day. As you will note, much of it parrallels Vlastos' view - only it is put much more simply and it ends the argument much sooner by clarifying what assumptions 1 and SP should be, (and thus, the notion of participation which is found in NI would serve to exclude F-ness from the regress).

Why is it that we speak in terms of Forms at all? Melling states that "when different things share the same name they do so in virtue of there being something to which the common name refers." 113 This cuts to the heart of the issue. Clearly, when you speak of many different particular $x$ 's you can't say that you recognize the individual to be an $x$ in virtue of itself, for this would not explain how you recognize the other $x^{\prime} s$ as $x^{\prime}$ s or why you would want to call them all $x$ when they differ as they do. However, the Form $x$ can be recognized as being $x$ without problems. This is because it is one, it is not many differing $x$ 's, it can be recognized as being $x$ in virtue of itself. We could even define a Form of $x$ as follows:

The Form of $x=d f$. that $x$ which can be recognized as $x$ in virtue of itself, that is, without making reference to any other object.

Hence, Vlastos' assumptions 1 and SP would be clarified so as to exclude the Form of $x$ from any notion 
of participation, and in such a way the form would escape Non-Identity, even without changing the Non-Identity assumption.

Along with this, and as a correction to Plato's theory, we might add that we should not speak of Forms which exist independently of the particulars with regards to concepts which are purely relational such as equality, similarity, or largeness. Further, it may be helpful to speak of certain Forms as being wholly embodied in all the particulars which exemplify the Form. Examples of such forms would be Personhood or Time.

In formulating such a notion of Forms, I think we can avoid the TMA and at the same time be true to the heart of Plato's doctrine.

It must be admitted that this response has not proven the existence of Platonic Forms, (although many phenomenological realists think this can be done). However, I do hope that while demonstrating where the famous Third Man Argument fails, I have also helped to clarify the true nature of the genuine essences which are the primary focus of chreontic philosophy. 


\section{NOTES}

1. See Joseph Seifert's Back to Things in

Themselves, (New York: Routledge and Kegan Paul Inc., 1987). Seifert argues that Husserl did indeed make a turn from realism to idealism, and this turn was not justified by the "things in themselves." See also Roman Ingarden, On the Motives which led Husserl to Transcendental Idealism, (The Hague: Martinus Nijoff, 1975).

2. Dietrich von Hildebrand, What is Philosophy?, (Milwaukee: The Bruce Publishing Co., 1960), 223.

3. Ibid., $223-224$.

4. Ibid., 223.

5. Herbert Spiegelberg, The Phenomenological Movement, 2nd ed., (The Hague: Martinus Nijhoff, 1965), 168 .

6. Ibid., 172 .

7. Ibid.

8. Ibid., 170

9. Ibid.

10. Hildebrand, What is Philosophy?, 225.

11. Ibid.

12. Josef Seifert, "Foreward", Alethia, 1, (1980), ii .

13. See Fritz Wenisch, "Insight and Objective Necessity", Alethia, 4, (1988).

14. Adolf Reinach, "Concerning Phenomenology", trans. Dallas Willard, Personalist, (1964) 211.

15. See William Marra, "Creative Negation", Warheit, Weissheit und Sein, ed. Balduin Schwarz, (Regensburg: Josef Habbel, 1970), 75 - 88 .

16. Reinach, Concerning Phenomenology, 213. 
17. Ibid., 215 .

18. Ibid., 218 .

19. Hildebrand, What is Philosophy?, 224.

20. Reinach, Concerning Phenomenology, 219.

21. Plato, Republic, 139-140.

22. Plato, Meno, 80 , e.

23. Ibid., 86 , b.

24. Hildebrand, What is Philosophy?, 101.

25. Ibid., $102-103$.

26. Ibid., 110 .

27. Ibid., 112 .

28. Plato, Parmenides, $130, \mathrm{~b}-\mathrm{e}$.

29. Ibid.

30. Seifert, Back to Things in Themselves, 42.

31. Androw Woznicki, A Christian Humanism: Karol Wojtyla's Existential Personalism, (New Britain, CT.: Mariel Publishing, 1980), 18 .

32. A. Krapiec, I-Man, ed. Francis Lescoe, (New Britain, CT: Mariel Publishing, 1980), xv.

33. Woznicki, A Christian Humanism, 19.

34. Ibid.

35. See Karol Wojtyla, The Acting Person, (Boston: D. Reidel Publ. Co., 1979): In this work, it seems that Wojtyla is fully aware of the vality and objectivity of analyzing an essence which appears to us "on the occasion of acting."

36. Hildebrand, What is Philosophy?, 222.

37. Seifert, Back to Things in Themselves, 10.

38. Hildebrand, What is Philosophy, 224.

39. Ibid., 223 . 
40. Dietrich and Alice von Hildebrand, The Art of Living, (Chicago: Franciscan Herald Press, 1965), 6.

41. Ibid., $6-7$.

42. See Fritz Wenisch, Die Philosophie und ihre Methode, (Salzburg: Universitatsverlag Anton Pustet, 1976).

43. Dietrich von Hildebrand, "Reinach as a Philosophical Personality", Alethia, III, (1984), xxv.

44. Adolf Reinach, Personalist, see footnote p. 1.

45. Ibid.

46. Adolf Reinach, Aletheia, III, 15.

47. Ibid., $16-17$.

48. Ibid., 18. The term 'intentionality' is not being used to convey the usual meaning of the word. Intentionality here refers to a conscious relation of the mind to an object.

49. Ibid., 19.

50. Ibid., 22 .

51. Ibid., $26-27$.

52. Ibid., 26 .

228.

53. Spiegelberg, The Phenomenological Movement,

54. Edith Stein, Life in a Jewish Family, trans. Josephine Koeppel, O.C.D., (Washington D.C.: ICS Publications, 1986), 259.

55. Alice von Hildebrand, interviewed by James $M$. DuBois, (1989). During an interview with Alice von Hildebrand I learned that Scheler lived with Dietrich von Hildebrand for a period of time after he lost his position in Munich. Hildebrand arranged for Scheler to deliver a seminar at local coffee houses and in return he would recieve direct payment from students. Hildebrand had previously taken a course on the History of Ethics from Scheler at Munich during the period when he was studying under the direction of Theodore Lipps.

56. Stein, Life in a Jewish Family, 259.

57. A further reason for Scheler's adoption of the 
French term was the fact that by this time Nietzsche's use of the word had made it a "terminus technichus." see Scheler, Ressentiment, 39.

58. Scheler, Ressentiment, 39.

59. Ibid., $45-46$.

60. Ibid., 48 .

61. Ibid., 49 .

62. Ibid., 52.

63. Ibid., 53 .

64. Ibid., 55.

65. Ibid., 58 .

66. Ibid., 73.

67. Ibid., 77 .

68. Ibid., $72-73$.

69. John Crosby and Josef Seifert, "Dietrich von Hildebrand Obituary," Aletheia, I, 221.

70. Dietrich von Hildebrand, The Heart, (Chicago: Franciscan Herald Press, 1977), 30.

71. Ibid., 32 .

72. Ibid., $37-38$.

73. Spiegelberg, The Phenomenological Movement, 222. Here spiegelberg cites the following as one of Hildebrand's most original contributions: "The conception of value blindness as a partial explanation of seeming disagreement in valuations. In studying this phenomenon Hildebrand points out and explores in detail three types of such insensitivity: (a) total moral value blindness, where the moral predicates are meaningless to the person thus afflicted; (b) partial moral value blindness, in which there is only blindness to certain types of moral values, such as the higher and subtler ones; (c) moral blindness in classifying, i.e., inability to subsume actual behavior under the types with which the valuer is otherwise familiar."

74. See C.S. Lewis, Abolition of Man, (New York: Macmillan Publishing Company, 1947). 
75. This notion is found in $\mathrm{Ch}$. 25. of Dietrich von Hildebrand, Ethics, (Chicago: Franciscan Herald Press, 1953).

76. See Gary Watson, ed., Freewill, (Oxford: Oxford University Press, 1982), 24 - 46. The aforementioned pages of this text contain reprints of the relevant articles written by Roderick Chisholm (1964), Bruce Aune (1967), and Keith Lehrer (1968) respectively.

77. Bruce Aune, Philosophical Argumentation, (unpublished manuscript, 1989), 3 .

78. Ibid. Aune parenthetically adds that "a material philosophical axiom is not a tautology or analytic truth but an elementary substantive one--something synthetic and apriori."

79. Aristotle, Topics, $100 \mathrm{a}, \mathrm{b}$.

80. Aristotle Posterior Analytics, $21 \mathrm{~b}, \mathrm{ff}$.

81. Aune, Philosophical Argumentation, 4.

82. Ibid., 5 .

83. Ibid., 7 .

84. Ibid., 11.

85. I first encountered a formal presentation of these three "verbal helps" in a discussion with Dr. Fritz Wenisch of the University of Rhode Island. The second example of a verbal help was given to me by him..

86. See Fritz Wenisch, Ethics, (unpublished manuscript, 1988), $12-13$.

87. R.M. Chisholm, Brentano and Intrinsic Value, (Cambridge: Cambridge University Press, 1986), 9.

88. Ibid.

89. Ibid.

90. See Hildebrand, Ethics, $312-313$.

91. Chisholm, Brontano and Intrinsic Value, 59. In the footnote Chisholm states that this is a paraphrase from Oskar Kraus, "Die Grundlage der Werttheorie," Philosophie Jahrbucher, 11, (1914).

92. Ibid. 
93. Ibid., 59.

94. Ibid., 60 .

95. Ibid., 12 .

96. Ibid., 5 .

97. Ibid., 14.

98. Ibid., 15.

99. Ibid., 16.

100. Plato, Parmenides, 132 a.

101. Ibid.

102. Ibid., 132 b.

103. G. Vlastos, "Plato's Third Man Argument (Parm. 132A1-B2): Text and Logic (TMA II)," (1969), reprinted in G. Vlastos, Platonic Studies, (Princeton: Princeton University Press, 1973).

104. Ibid.

105. Ibid.

106. Ibid.

107. Ibid.

108. Plato, Parmenides, 132 b.

109. Vlastos, Platonic studies.

110. Ibid.

111. G. Vlastos, "The Third Man Argument in the Parmenides," (1954), reprinted in R.E. Allen, studies in Plato's Metaphysics, (London: Routledge \& Kegan Paul, 1967).

112. Ibid.

113. David J. Melling, Understanding Plato, (New York: Oxford University Press, 1987), p. 119. 


\section{SELECTED BIBLIOGRAPHY}

Aune, Bruce. Philosophical Argumentation. Unpublished manuscript, 1989.

Chisholm, R. M. Brentano and Intrinsic Value. Cambridge: Cambridge University Press, 1986.

Crosby, John, Josef Seifert, "Dietrich von Hildebrand Obituary." Aletheia, I.

Husserl, Edmund. Phenomenology and the Crisis of

Philosophy. trans. Quentin Lauer. New York: Harper \& Row, 1965.

- Logical Investigations. trans. J.N.

Findlay. New York: Humanities Press, 1970.

Ingarden, Roman. On the Motives Which led Husserl to

Transcendental Idealism. The Hague: Martinus

Nijhoff, 1975 .

Krapiec, A. I - Man, ed. Francis Lescoe. New

Britain, CT: Mariel Publishing, 1980.

Lewis, C. S. The Abolition of Man. New York: Macmillan Publishing Company, 1947 .

Marra, William. "Creative Negation", Warheit, Weissheit und Sein. Ed. Balduin Schwarz. Regensburg: Josef Habbel, 1970 .

Melling, David, J. Understanding Plato. New York: Oxford University Press, 1987.

Pfaender, Alexander. Phenomenology of Willing and

Motivation. Trans. Herbert Spiegelberg.

Northwestern: Northwestern University Press, 1967.

Plato Meno.

- Parmenides.

- Phaedrus.

- Republic. 
- Theatetus.

Reinach, Adolf. "Concerning Phenomenology", Trans. Dallas Willard, Personalist, 1964.

Reinach, Adolf. "The Apriori Foundations of the Civil

Law." Trans. John Crosby. Aletheia III, 1983.

Scheler, Max. Ressentiment. Ed. Lewis A. Coser. Trans.

William Holdheim. New York: The Free Press of

Glencoe, 1961 .

Seifert, Josef. "Foreward", Alethia, I, 1980.

- Back to Things in Themselves. New York:

Routledge \& Kegan Paul Inc., 1987.

Spiegelberg, Herbert. The Phenomenological Movementv. 2.

The Hague: Martinus Nijhoff, 1965.

Stein, Edith. Life in a Jewish Family. Trans. Josephine Koeppel. O.C.D. Washington D. C.: ICS Publications, 1986.

Vlastos, G. "The Third Man Argument in the Parmenides" 1954. Reprinted in R. E. Allen. Studies in Plato's Metaphysics. London: Routledge \& Kegan Paul, 1967.

- "Plato's Third Man Argument

(Parm. 132A1-B2): Text and Logic (TMA II)" 1969.

Reprinted in G. Vlastos. Platonic Studies.

Princeton: Princeton University Press, 1973.

Von Hildebrand, Alice. "Interviewed by James M. DuBois," 1989:.

Von Hildebrand, Dietrich. Ethics. Chicago: Franciscan Herald Press, 1953.

- What is Philosophy? Milwaukee: The Bruce Publishing Company, 1960. 1977 .

- The Heart. Chicago: Franciscan Herald Press,

Von Hildebrand, Dietrich and Alice. The Art of Living.

Chicago: Franciscan Herald Press, 1965.

Watson, Gary. Freewill. Oxford: Oxford University Press, 1982.

Wenisch, Fritz. "Insight and Objective Necessity", 
Alethia, IV, 1988 .

- Ethics. Unpublished manuscript, 1988.

Wojtyla, Karol. The Acting Person. Boston: D. Reidel

Publishing Company, 1979.

Woznicki, Andrew. A Christian Humanism: Karol Wojtyla's Existential Personalism. New Britain, CT.: Mariel Publishing, 1980 . 